\title{
Role of sleep quality in the metabolic syndrome
}

\section{Dorit Koren ${ }^{1,2}$ \\ Magdalena Dumin' \\ David Gozal ${ }^{2,3}$}

'Section of Adult and Pediatric Endocrinology, Diabetes, and Metabolism, Department of Medicine, ${ }^{2}$ Section of Pediatric Sleep Medicine, ${ }^{3}$ Section of Pulmonology, Department of Pediatrics, Pritzker School of Medicine, Biological Sciences Division, The University of Chicago, Chicago, IL, USA

\section{Video abstract}

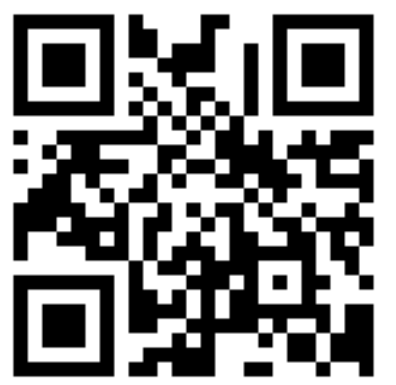

Point your SmartPhone at the code above. If you have a QR code reader the video abstract will appear. Or use: http://youtu.be//YrirlkBvigo

Correspondence: David Gozal Section of Pediatric Sleep Medicine, Department of Pediatrics, Pritzker School of Medicine, Biological Sciences Division, The University of Chicago, Knapp Center for Biomedical Discovery, Room 4100 , 900 East 57th Street, Mailbox 4, Chicago, IL 60637, USA

Tel +I 7737023360

Fax + I 7739260756

Email dgozal@uchicago.edu
This article was published in the following Dove Press journal:

Diabetes, Metabolic Syndrome and Obesity:Targets and Therapy 25 August 2016

Number of times this article has been viewed

Abstract: Emerging evidence has assigned an important role to sleep as a modulator of metabolic homeostasis. The impact of variations in sleep duration, sleep-disordered breathing, and chronotype to cardiometabolic function encompasses a wide array of perturbations spanning from obesity, insulin resistance, type 2 diabetes, the metabolic syndrome, and cardiovascular disease risk and mortality in both adults and children. Here, we critically and extensively review the published literature on such important issues and provide a comprehensive overview of the most salient pathophysiologic pathways underlying the links between sleep, sleep disorders, and cardiometabolic functioning.

Keywords: sleep apnea, circadian clock, insulin resistance, obesity, cardiovascular risk

\section{Introduction}

Obesity has reached epidemic proportions worldwide - in the US, $17 \%$ of children are now overweight or obese. ${ }^{1-3}$ In parallel, there has been a rise in the prevalence of obesity-related comorbidities, such as insulin resistance (IR), type 2 diabetes mellitus (T2DM), and the metabolic syndrome (MetS), collectively referred to as cardiometabolic risk. ${ }^{4,5}$ The MetS is a cluster of metabolic disorders encompassing central obesity, impaired fasting glucose, dyslipidemia (specifically, triglyceride elevation and/or low levels of high-density lipoprotein [HDL] cholesterol), and hypertension and is associated with an increased risk of T2DM and, in adulthood, cardiovascular disease (CVD) and overall mortality. ${ }^{6,7}$ The underlying pathophysiology of MetS is thought to include IR and/or an inflammatory state, which accompanies obesity. ${ }^{8,9}$ The specific criteria for the MetS in adults have been defined by the National Cholesterol Education Program or Adult Treatment Panel III and the World Health Organization. The MetS is now endemic in the US $-35 \%$ of all adults and $50 \%$ of those older than 60 years suffer from this condition. ${ }^{10}$ The prevalence of the MetS phenotype in children has also increased, doubling between 1988 and 2006 , from $4 \%$ to $8.6 \%{ }^{11,12}$ The prevalence of the MetS in obese children and adolescents varies somewhat depending on ethnicity and on which specific pediatric diagnostic criteria are used (as there is no specific consensus on the definition of the MetS in children) but ranges between $30 \%$ and $50 \%$, with higher prevalence in those with more severe obesity. ${ }^{13-18}$ The underlying etiology of the rise in the frequency of these conditions is multifactorial, with well-recognized contributions from diet (large portion sizes, nutrient-dense foods, and others) and physical inactivity; ${ }^{19}$ however, such factors alone do not explain the significant epidemic of obesity and the MetS. 
There is increasing recognition that disturbances of sleep, including chronic sleep restriction and alterations in sleep architecture, such as obstructive sleep apnea, and other causes of sleep disruption and fragmentation, are also the risk factors for obesity and cardiometabolic risk in both adults and children. Most recently, a body of data has begun to emerge on the links between chronotype and circadian rhythm disorders and obesity and the MetS. In this review, we focus on the contributions of disturbances of sleep and circadian biology to the development of obesity, IR, and the MetS in adults, prepubertal children, and adolescents, with a special emphasis on the potential mechanisms underlying these links, as these serve as potential targets for preventing the MetS and its complications.

\section{Sleep restriction and sleep architecture: impact on the MetS and cardiometabolic risk in adults and children}

\section{Chronic sleep restriction}

Chronically insufficient sleep is endemic and has been declared as a public health problem by the Centers for Disease Control. ${ }^{20}$ Recent data from the 2014 Behavioral Risk Factor Surveillance System poll found that $41.3 \%$ of the 44,306 adults polled reported $\leq 6$ hours $(11.8 \% \leq 5$ hours) of sleep, $29.5 \%$ reported 7 hours, $27.7 \%$ reported 8 hours, $4.4 \%$ reported 9 hours, and $3.6 \%$ reported $\geq 10$ hours; taking into account the sleep durations of 7-9 hours recommended for age, only $65.2 \%$ reported obtaining the recommended healthy sleep duration. ${ }^{21}$ In studies of children and adolescents, $\sim 27 \%$ of school-aged children and $45 \%$ of adolescents report sleeping less than recommended for age, ${ }^{22,23}$ with lower levels of parental education, lack of regular enforcement of rules about caffeine, and presence of electronics in the child's bedroom overnight being the most predictive of age-adjusted insufficient sleep duration. ${ }^{24}$

In adult and pediatric populations, chronic sleep restriction and poor sleep quality are associated with an increased risk of obesity, IR, and the MetS or components thereof. ${ }^{25-33}$ Epidemiological adult studies have also found associations between insufficient sleep, and in some cases, long sleep duration and T2DM risk, T2DM severity, and CVD incidence and mortality. ${ }^{34-39}$ Epidemiological reports cannot ascertain causality; however, numerous laboratory sleep restriction studies have now demonstrated the causal nature of the relationship between behavioral sleep restriction and obesity, IR, and changes in other metabolic functions that together lead to MetS. These data and recent updates are discussed in greater detail in the following sections.

\section{Epidemiological data}

\section{Adults}

A large body of evidence has emerged over the last 50 years implicating insufficient and/or excessive sleep duration in allcause mortality and in CVD and cardiometabolic risk factors, including the MetS, a cluster of interrelated CVD risk factors (central obesity, elevated triglycerides, low HDL, hypertension, and elevated fasting glucose). Later, we examine the associations between sleep duration and elements comprising cardiometabolic risk, as well as all-cause mortality.

\section{Sleep duration and all-cause mortality}

The first study to report an association between insufficient sleep and mortality was a study of 1,064,004 adults aged $<30$ to $>80$ years published in 1964 , which found that those reporting a sleep duration of 7 hours had the lowest mortality rate. ${ }^{40}$ Similarly, in 1983, the Alameda County Study found that men sleeping for $<6$ hours or $>9$ hours exhibited a 1.7-fold greater total age-adjusted death rate vs men sleeping for 7-9 hours per night and that women with shorter vs normal sleep durations had a 1.6-fold greater relative mortality risk. ${ }^{41}$ A number of prospective cohort studies conducted since these early landmark studies have also found an inverse relationship between sleep duration and all-cause mortality risk in a number of different populations, and a 2010 meta-analysis of all relevant prospective cohort studies of $>3$ years duration found that both short sleep durations (variably defined as $<4$ hours to $<7$ hours) and long sleep durations (variably defined as $>8$ hours to $>12$ hours) were associated with greater all-cause mortality risk (short sleep: relative risk [RR] $1.12,95 \%$ confidence interval [CI] 1.06-1.18; long sleep: RR 1.30, CI 1.22-1.38). ${ }^{42} \mathrm{~A}$ more recent meta-analysis found a J-shaped relationship between all-cause mortality and sleep duration, with greatest RR seen in long sleepers rather than short sleepers; subgroup analyses showed that short sleep duration ( $<7 \mathrm{~h} /$ night) increased the RR of all-cause mortality in women but not in men. ${ }^{43}$

Thus, a number of prospective cohort studies have now found that insufficient and/or long sleep is associated with an increased all-cause mortality over time, with a variable degree of risk. Alterations of sleep duration associate with a number of different conditions, which could increase the risk of all-cause mortality; while an entire enumeration is outside the scope of this review, many of these are examined later.

\section{Sleep duration and obesity}

The secular trends of chronic sleep restriction have paralleled those of obesity in recent years, suggesting epidemiological 
links between the two. Indeed, hundreds of studies in adult and pediatric populations have now been published examining the associations between insufficient sleep and obesity risk. The plurality of such studies in adults and the majority of the studies in children have found that insufficient sleep is associated with an increased risk of obesity. A 2008 meta-analysis of epidemiological studies that encompassed 634,511 participants $(30,002$ children and 604,509 adults) aged from 2 years to 102 years found a pooled odds ratio (OR) for short sleep duration (usually defined as $\leq 5$ hours in adults and $\leq 10$ hours in children) and obesity of 1.55 (range 1.43-1.68) in adults and 1.89 (range 1.46-2.43) in children. ${ }^{25}$ Since then, the majority of cross-sectional or longitudinal studies have reported significant associations between short sleep duration and overall obesity risk and/ or central adiposity, ${ }^{44-46}$ although it should be stressed that some of the studies did not find significant associations after adjusting for other variables. ${ }^{47}$ Interestingly, the relationship between sleep duration and obesity is not necessarily linear; the Wisconsin Sleep Cohort Study found an U-shaped association between sleep duration and obesity, wherein both short and long sleep durations link to an increased risk for the presence of a higher body mass index (BMI); the lowest BMI was seen in individuals sleeping for an average of $7.7 \mathrm{~h} /$ night. $^{48}$ Similarly, a longitudinal follow-up cohort study with $\sim 6$ years average follow-up found that both short sleepers ( $\leq 6$ hours) and long sleepers ( $>9$ hours) are more likely to accumulate visceral adipose tissue (assessed by computerized tomography) than those sleeping 7-8 hours and that those who switched from sleeping $\leq 6$ hours to sleeping 7-8 hours accumulated less visceral adipose tissue. ${ }^{46}$ In contrast, analysis of data from 13,742 participants aged $\geq 20$ years from the 2005-2010 National Health and Nutrition Examination Survey (NHANES) examining associations between sleep duration and obesity risk did not find such an U-shaped relationship. In this cohort, in which participants were categorized as short sleepers ( $\leq 6 \mathrm{~h} /$ night), average sleepers (7-9 h/night), or long sleepers ( $\geq 10 \mathrm{~h} /$ night), a negative linear association was found between sleep duration and both BMI and waist circumference among participants without depression or a diagnosed sleep disorder and without notable differences by race or sex, but with regression coefficients that were notably stronger among adults aged 20-39 years. In other words, short sleepers were more likely to be overall obese and to have abdominal adiposity, especially in the young-middle age adult groups. ${ }^{49}$ While this study did not find that the sleep-obesity risk differed by race or ethnicity, other studies have found variations in the relationship between short sleep and obesity in other ethnic groups,${ }^{50,51}$ including one large study that found that the risk of obesity with short sleep duration was significantly greater in African Americans than in Caucasians. ${ }^{52}$ Variations in the associations between short sleep and obesity by ethnicity have also been noted in other studies.

Thus, the preponderance of the epidemiological evidence suggests that insufficient sleep increases the OR of being or becoming obese. As discussed in subsequent sections, the risk of obesity-related comorbidities is also increased by insufficient sleep.

\section{Sleep duration and hypertension}

Hypertension, a component of the MetS, is a well-known cardiovascular risk factor; alterations in sleep duration have been associated with an increased risk of developing this condition. The Sleep Heart Health Study, a long-term longitudinal multicenter cohort study of sequelae of sleep and sleep-disordered breathing, examined 2,815 men and 2,097 women aged 30-100 years and found that hazard ratios (HRs) for hypertension increased with insufficient sleep duration ( $<6$ hours, HR 1.66, CI 1.35-2.04; 6 hours to $<7$ hours, HR 1.19, CI 1.02-1.39) and with prolonged sleep duration ( 8 hours to $<9$ hours, HR 1.19, CI 1.04-1.37; $>9$ hours, HR 1.30, CI 1.04-1.62).${ }^{53}$ In the same year, data from the first NHANES survey of 4,810 men and women, aged 32-59 years at baseline who were followed for nearly four decades, showed that sleep duration of $\leq 5 \mathrm{~h} /$ night was associated with a significantly increased risk of incident hypertension (HR 2.10, CI 1.58-2.79), an association that held up after adjusting for confounders. ${ }^{54}$ Other studies have also found associations between risk of hypertension and both short sleep duration and long sleep duration. ${ }^{45,55}$ Age may modulate the relationship between sleep duration and hypertension; several studies suggested that the association between short sleep duration and/or long sleep duration is stronger in younger and middle-aged adults than in older adults; indeed, several studies have found no association between sleep duration and risk of hypertension in adults older than 58 years, 60 years, or 65 years, possibly because other risk factors for hypertension mask such association. ${ }^{55-58}$ Other studies have found that the association between insufficient sleep and high blood pressure is greater in premenopausal women vs postmenopausal women. ${ }^{59}$ Interestingly, the association between sleep duration and hypertension risk may differ in degree and in directionality between men and women: the Whitehall II study of 10,308 English men and women aged $35-55$ years at baseline, who were followed for 
an average of 15 years, found that the association between short sleep and hypertension risk was detectable in women but not in men. ${ }^{60}$ Other studies in different populations have also found that the associations between insufficient sleep duration and hypertension are stronger in women than in men. ${ }^{59}$ At the other end of the sleep duration spectrum, at least one study reported that the association between long sleep duration and hypertension risk is detectable in men but not in women. ${ }^{61}$ These findings suggest that in adults, there may be age- and sex-specific sensitivity to the detrimental effects of chronic sleep deprivation.

\section{Sleep duration, IR, and T2DM}

In the past 25 years, there has been an explosion of studies linking insufficient sleep with the risk of IR, incident type 2 diabetes, and poorer glycemic control in adults with T2DM;35,62-64 long sleep duration ( $\geq 9$ hours) has also been associated with an increased risk of IR and incident T2DM. ${ }^{62,65,66}$ The association between sleep duration and incident T2DM risk in multiethnic cohorts may be modulated by ethnicity, although the relationship is unclear: one study found that non-Hispanic whites and Hispanic adults sleeping for $\leq 7$ hours vs 8 hours were predisposed to T2DM, while African American participants were not, ${ }^{67}$ while another study that used data from a nationally representative sample of $>130,000$ Caucasian and African American NHANES participants found a U-shaped rather than a linear relationship between sleep duration and likelihood of T2DM (both sleeping for $<7$ hours and $>8$ hours associated with the risk of T2DM), which was stronger in the Caucasian participants, but found that the ethnic disparities were significantly attenuated after adjusting for socioeconomic status, suggesting that societal rather than biological factors might be partially responsible for ethnic disparities in these relationships. ${ }^{68}$ Interestingly, a recently published study of a multiethnic cohort found that the associations between short sleep duration ( $<7 \mathrm{~h} /$ night) and obesity, T2DM risk, and cardiovascular risk factors varied between the different cohorts examined. ${ }^{51}$ Thus, chronic sleep restriction and potentially excessive sleep duration appear to increase the risk of IR and T2DM, this relationship being modulated by age, race, and ethnicity, although the degree to which these differences have underlying biological rather than socioeconomic underpinnings remains uncertain.

\section{Sleep duration, the MetS, and CVD}

A number of studies in a wide variety of cohorts of different ethnic backgrounds and in both men and women have now shown that sleep duration is a risk factor for the MetS. ${ }^{69-74}$ In a cohort of 1,214 adults participating in the Adult Health and Behavior Project registry, being a short or a long sleeper increased the OR of having the MetS by $45 \% .{ }^{33}$ While the association between insufficient sleep and risk of the MetS is detected in most studies, the association between longer sleep and MetS is less consistent. ${ }^{72,75}$ Interestingly, one study found that after adjusting for confounders, long ( $\geq 9$ hours) but not short ( $<6$ hours) sleep duration was associated with an increased risk of the MetS. ${ }^{76}$ A recent meta-analysis of 18 studies encompassing 75,657 participants and using adults sleeping for 7-8 hours as a reference group found a doseresponse relationship between sleep duration and the MetS, with increasing risk of the MetS in sleep categories all the way up to a 1.5 -fold OR (95\% CI 1.1-2.08, $P=0.01)$ among those sleeping for $<5 \mathrm{~h} /$ night; however, they did not find a significant association between long sleep duration and the MetS - OR $1.13(95 \%$ CI, 0.97-1.32; $P=0.10) .{ }^{71}$ The question of causality is difficult to assess in cross-sectional studies; however, a prospective cohort study of 2,579 adults aged 40-70 years without MetS at baseline, who were followed for an average of 2.6 years, found a significantly higher risk of incident MetS for those sleeping for $<6$ hours - adjusted OR (95\% CI) 1.41 (1.06-1.88). Breaking the MetS down to its components, short sleepers had higher OR (95\% CI) for elevated waist circumference (1.30 [0.98-1.69]), low HDL cholesterol (0.75 [0.56-0.97]), elevated triglycerides $(0.82$ [0.60-1.11]), high blood pressure (1.56 [1.19-2.03]), and high fasting glucose (1.31 [0.96-1.79]). ${ }^{77}$

Given the associations between insufficient or prolonged sleep duration and the many cardiovascular risk factors enumerated in the sections examining associations between sleep duration and all-cause mortality, hypertension, and T2DM above, it is, therefore, unsurprising that an association exists between sleep duration and CVD. Several large prospective cohort studies published in recent decades have indicated that insufficient sleep duration and long sleep duration are associated with an increased risk of coronary heart disease (CHD) and its predisposing risk factors. The Whitehall II study of 10,308 adult English men and women aged 35-55 years at baseline, who were followed for an average of 15 years, found that participants with short sleep duration ( $\leq 6$ hours) and restless, disturbed sleep had the highest hazard ratios of CHD (RR: $1.55,95 \%$ CI: $1.33-1.81) .{ }^{78}$ Similarly, in the Nurses' Health Cohort of 71,617 US female health professionals, aged 45-65 years and after 10 years of follow-up, the adjusted RR values (95\% CIs) of CHD for individuals reporting 5 or fewer, 6 , and 7 hours of sleep per night on 
average were 1.45 (1.10-1.92), 1.18 (0.98-1.42), and 1.09 (0.91-1.30), respectively. The RR for $\geq 9$ hours of sleep was 1.38 (1.03-1.86). ${ }^{79} \mathrm{~A}$ number of other studies have found similar results in a variety of different adult populations of varying ages and ethnic backgrounds: some have found associations only between insufficient sleep (with or without poor sleep quality) and CHD risk and/or mortality, ${ }^{37}$ while others have found U-shaped associations, with both short sleep and excessive sleep being associated with an increased risk of CHD ${ }^{80,81}$ In particular, a 2011 meta-analysis found that short sleep duration was associated with a greater risk of incident CHD and CHD mortality (RR 1.48, 95\% CI 1.22-1.80) and incident stroke (RR 1.15, 95\% CI 1.00-1.31), while long sleep duration was associated with a greater risk of incident CHD (RR 1.38, 95\% CI 1.15-1.66), stroke (RR $1.65,95 \%$ CI 1.45-1.87), and total CVD (RR 1.41, 95\% CI 1.19-1.68). ${ }^{39}$ More recently, a prospective cohort study of 8,128 Dutch men and 9,579 Dutch women aged 20-65 years, free of CVD at baseline and followed for 10-14 years, found that in the context of eating a healthy diet, maintaining a moderate level of physical activity, nonsmoking status, and moderate alcohol consumption, sleeping sufficiently (defined as $>7$ years) lowered composite CVD risk by $65 \%$ (HR 0.35 , 95\% CI $0.23-0.52$ ) and lowered the risk of fatal CVD by $83 \%$ (HR 0.17, 95\% CI 0.07-0.43). ${ }^{82}$ Additionally, several studies have found that the risk between sleep duration and CHD is modulated by sex, with some studies showing higher risk of incident myocardial infarction in women vs men who were short or long sleepers ${ }^{83,84}$ and others showing no difference in risk by sex. ${ }^{39}$ Age may also modify the association, as one study reported an U-shaped association between sleep duration and cardiovascular mortality risk, an association that was stronger in females than in males and stronger in older adults than in younger adults.

In summary, a large number of cross-sectional and prospective epidemiological studies have demonstrated that restricted sleep and, less consistently, longer sleep duration predispose to obesity, IR, T2DM, MetS, CVD, and all-cause mortality.

\section{Children and adolescents}

\section{Normal sleep in childhood}

Normal sleep duration varies across the lifespan. Recently, the National Sleep Foundation convened an 18-member multidisciplinary expert panel and issued an expert set of guidelines reflecting sufficient sleep duration across the lifespan: 14-17 hours for newborns, $12-15$ hours for infants, 11-14 hours for toddlers, $10-13$ hours for preschoolers,
9-11 hours for school-aged children (aged 6-13 years), and 8-10 hours for adolescents (aged 14-18 years), as compared to 7-9 hours in young adults and middle-aged adults. ${ }^{85}$

\section{Epidemiology of insufficient sleep}

Insufficient sleep is widespread. The 2014 Sleep in America Poll found that $30 \%$ of school-age children aged 6-11 years (as reported by their parents) sleep less than the recommended 9 hours. ${ }^{86}$ However, the prevalence of behavioral sleep restriction increases substantially in adolescents: the 2006 National Sleep Foundation Sleep in America poll found that $45 \%$ of children aged $11-17$ years and $75 \%$ of twelfth graders surveyed reported $<8 \mathrm{~h} /$ night of sleep, ${ }^{87}$ and in the 2009 United States Youth Risk Behavior Survey, only 31\% of adolescents polled (28\% of females and $33 \%$ of males, with some variability across ethnic groups) reported $\geq 8 \mathrm{~h} /$ night of sleep ${ }^{88}$ Sleep durations may vary in children of different ethnic and/or socioeconomic backgrounds: one study that objectively measured sleep using actigraphy in African American and Caucasian 14-18-year olds in the US found that sleep insufficiency was even more prevalent among African American than Caucasian adolescents, ${ }^{89}$ and a recent study of 9-10-year-old children in the UK found that white European children slept longer than South Asian and Black African children. ${ }^{90}$ The preponderance of epidemiological data, thus, clearly shows that chronic short sleep is a problem that has its roots in childhood and adolescence.

\section{Sleep duration and obesity}

The epidemic of short sleep imposes health sequelae in childhood. While not every study has found an association between sleep duration and obesity, ${ }^{91}$ the majority of cross-sectional and longitudinal studies have shown that insufficient sleep duration in children associates with concurrent or long-term risk of obesity - in infancy, ${ }^{92}$ early childhood, ${ }^{93-95}$ schoolage years, ${ }^{94,96-98}$ and adolescence. ${ }^{97,99,100} \mathrm{~A}$ meta-analysis of 13 pediatric studies that included $>30,000$ children found a pooled OR of 1.89 for obesity in children who were short sleepers. ${ }^{25}$ However, short sleep duration may not be the only factor in play: obese children were found to be less likely than their nonobese peers to experience catch-up sleep on the weekends. ${ }^{101}$ Interestingly, the same pattern may not hold true in adolescents, where high variability in sleep duration may predispose to higher energy intake and more snack consumption. ${ }^{102}$ Shorter sleep duration in childhood may also promote adult obesity independently of childhood BMI, parental BMI, and adult sleep duration. ${ }^{103}$ Some studies have shown associations in males but not in females, ${ }^{98,104}$ 
while other studies have shown similar associations in both sexes. ${ }^{105}$ Several studies have reported that short sleep in childhood and adolescence is associated with a higher waist circumference, a surrogate measure of visceral adiposity and one of the features of the MetS. ${ }^{96,106-108}$ In a UK study, sleep duration associated negatively not only with the ponderal index (a measure of adiposity) but also with fat mass - that is, school children who slept less had greater adipose tissue mass than children who slept more. ${ }^{90}$ Again, sleep deprivation may have adverse metabolic effects later in life: a recent prospective cohort study of 3,964 Brazilian children assessed at the age of 11 years and 18 years found that in girls those with insufficient self-reported sleep duration at age 11 years but sufficient sleep duration at age 18 years, were more likely to have higher BMI and fat mass than their peers with adequate sleep at both time points. ${ }^{109}$ Thus, sleep restriction and lack of catch-up sleep on weekends in children and adolescents appear to associate with an increased risk of increased weight gain, central obesity, and increased fat mass that can possibly persist or become apparent several years later.

\section{Sleep duration associations with the MetS and its components}

A number of studies have now found associations of chronic short sleep duration in children and adolescents with elements of the MetS.

\section{High blood pressure}

Chronic sleep restriction has been found to associate with an increased blood pressure in children and adolescents. ${ }^{108,110-112}$ Poor sleep quality is also associated with higher blood pressure in obese adolescents. ${ }^{113}$ This association may be primarily driven by the blunting of the usual nocturnal dip in blood pressure: insufficient actigraphically measured sleep duration was associated with elevated nocturnal blood pressures in African American and Caucasian adolescents independently of BMI. ${ }^{114}$ Interestingly, variability in sleep patterns and sleep duration may also have adverse effects: the Penn State Child Cohort study recently found that an increased sleep variability associated with a decreased heart rate variability, ${ }^{115}$ a marker of cardiovascular risk. Studies of younger children have been more equivocal than studies in adolescents regarding the association between sleep duration and blood pressure. One study found that this association was primarily mediated by BMI rather than sleep duration per se, ${ }^{116}$ and another study found that while short sleep duration was associated with lower sympathetic nervous system activation and higher cardiac activation under stress (both risk factors for high blood pressure), there was no association with blood pressure itself. ${ }^{117}$ Thus, while the association between insufficient sleep and hypertension risk in adolescents is similar to that data in adults, the impact in younger children is less obvious.

\section{IR and T2DM risk}

Although there are considerably less available data in children examining these associations than in adults, several studies have shown that insufficient sleep is associated with IR in obese children (but not in normal-weight children) and normal-weight and obese adolescents independently of obesity. ${ }^{18-121}$ Lower sleep efficiency (the percentage of time in bed that is spent asleep) also predisposes to IR in overweight and obese adolescents. ${ }^{121}$ In one study, more variability in sleep duration was associated with higher insulin levels. ${ }^{101}$ In at least one study of adolescents, long sleep duration ( $>10$ hours overnight) was also associated with greater IR, ${ }^{119}$ but these findings have not yet been replicated.

The majority of studies in children examining the association between sleep duration and insulin sensitivity have utilized either fasting insulin measures or the homeostasis model assessment of IR calculated from fasting insulin and glucose levels, but one recent study notably examined associations between self-reported habitual sleep duration and insulin sensitivity as measured by the gold standard hyperinsulinemic-euglycemic clamp in 615 obese adolescents and found that adolescents sleeping for $<8$ hours had lower insulin sensitivity even after controlling for age and sex. ${ }^{122}$

Few pediatric studies have examined associations between sleep duration and glycemic levels. A study of Chinese preschool-age children (aged 3-6 years) found that short sleep duration of $<8$ hours was associated with higher fasting glucose in obese but not in nonobese children. ${ }^{123}$ Duration of slow wave (nonrapid eye movement stage 3 slow wave sleep) sleep has also been found to associate positively with insulin sensitivity and insulin secretion, both of which are protective against the development of T2DM. ${ }^{124,125}$ Shorter sleep duration has also been found to associate with higher fasting and postglucose challenge (during oral glucose tolerance test) glucose levels in normal-weight and obese children. ${ }^{124,126}$ One study in obese adolescents found U-shaped associations between sleep duration in the sleep lab and fasting glucose, postchallenge glucose levels, and hemoglobin A1C (HbA1C), with both short sleep (especially $<6$ hours) and long sleep durations being associated with greater levels. ${ }^{125}$ While these studies do suggest that insufficient (and perhaps long) sleep duration would increase the risk of developing T2DM in children older than 10 years (the age at which the risk 
of developing diabetes rises to appreciable levels) $)^{127}$ and adolescents, we are not aware of any pediatric data examining the associations between sleep duration and incident T2DM, or the impact of sleep on glycemic control in those children with existing T2DM.

\section{Dyslipidemia}

The data on associations between sleep duration and dyslipidemia in children and adolescents are conflicting. One study found that sleep duration in children is directly associated with HDL cholesterol levels (ie, longer sleepers had higher HDL levels), ${ }^{119}$ and another study found that sleep duration in children and adolescents is inversely associated with high total cholesterol/high low-density lipoprotein (LDL) levels (ie, longer sleepers had lower LDL and total cholesterol levels). ${ }^{98}$ In the National Longitudinal Study of Adolescent Health study, in which adolescents were followed up for an average of 7 years, a significant longitudinal association between insufficient sleep duration in adolescence and risk of being diagnosed with hypercholesterolemia emerged in females but not in males. ${ }^{128}$ Not all studies show linear associations between sleep duration and dyslipidemia; long sleep duration may be a risk factor for dyslipidemia as well, as one study of Korean adolescents found that long sleep duration but not short sleep duration was associated with hypertriglyceridemia, ${ }^{129}$ and a study of Iranian children and adolescents found that long sleep duration ( $>8$ hours) was associated with higher LDL levels in females and higher total cholesterol levels in males. ${ }^{130}$ Additionally, several other studies found no significant associations between sleep duration and lipid levels in children and adolescents, ${ }^{131-133}$ and the 2007-2009 Canadian Health Measures Survey found that there were no significant associations between sleep duration and lipid levels after adjusting for body weight. ${ }^{97}$ Thus, sleep duration (short and/or long) may associate with dyslipidemia in children and adolescents, but the association may be mediated by obesity.

\section{MetS risk}

Data in children regarding associations between sleep duration and MetS risk are sparse and mostly negative: one study of 723 8-11-year-old Danish children reported that insufficient sleep (among other risk factors) was associated with a number of elements comprising the MetS (a "MetS score"). ${ }^{134}$ Similarly, a recent study of 1,361 Malaysian adolescents aged 13 years found an U-shaped association between self-reported sleep duration and MetS risk, with the lowest risk seen in those sleeping for 7-9 hours. ${ }^{135}$ However, several other clinic and population-based studies in children and adolescents have failed to find an association between sleep duration and the MetS. ${ }^{129,131,133,136}$

In summary, insufficient sleep and, less consistently, long sleep in children and adolescents is associated with obesity and with several components of the MetS, including higher blood pressures (more consistently in adolescents and inconsistently in younger children), and with higher glucose levels in a few adolescents studies, the association of sleep duration and dyslipidemia is highly inconsistent; evidence regarding an association between sleep duration and the MetS in children and adolescents is lacking. The obvious divergence from the findings in adults may be in part because there are several different competing definitions of the MetS in children or because the more chronic sequelae of sleep restriction may require time to develop and become manifest. IR is thought to be a central component of the pathophysiology of the MetS; it is interesting that the associations between sleep duration and IR are more consistently reported in adolescents, while in prepubertal children, these associations have been primarily reported in those who are obese and thus already predisposed to IR. Thus, future studies should focus on adolescents.

\section{Experimental evidence and pathophysiology}

\section{Adults}

Experimental sleep restriction, even in healthy and lean young adults, can lead to adverse metabolic consequences. Although no human studies have shown that experimental changes in sleep restriction induce the entirety of the MetS, experimental sleep restriction studies have examined the impact of sleep deprivation on weight gain and on individual components making up the MetS.

\section{Alterations in sleep duration and obesity}

As discussed above in the sleep duration and obesity section, epidemiological studies show that insufficient sleep is independently associated with an increased risk of obesity; in fact, even a few days of experimental sleep restriction to $4 \mathrm{~h} /$ night can lead to a mean $1 \mathrm{~kg}$ weight gain in just 4 days, ${ }^{137}$ despite increases seen in 24-hour energy expenditure in some studies (though not in others). ${ }^{137-141}$ These a priori paradoxical findings are at least partially explained by the increase in subjective hunger and in energy intake (at mealtimes and/ or as snacks, often late at night) in sleep-restricted adults allowed free access to food during experimental sleep restriction (although the increase in sleep deprivation-related caloric intake may be greater in men than in women ${ }^{139,142}$ ), exceeding the sleep restriction-induced increase in energy expenditure. ${ }^{137,139,141-144}$ In addition, a change in macronutrient 
distribution of food intake favoring (variably) either more carbohydrates or more high-fat foods further accounts for the positive energy intake balance. ${ }^{141,142}$ Experimental sleep restriction has also been found to reduce physical activity in adults with T2DM. ${ }^{145}$ Conversely, a pilot study to extend sleep in ten overweight adults found that caloric intake decreased and that the participants expressed a decreased desire for sweet and salty foods. ${ }^{146}$ Alterations in the anorexigenic adipocyte-derived hormone leptin and the orexigenic gut hormone ghrelin may play a role: lower leptin and higher ghrelin in most though not all experimental sleep restriction studies in adults were reported. ${ }^{48,147,148}$ However, some studies find higher rather than lower leptin levels, suggesting leptin resistance, ${ }^{149}$ and other studies find no change in leptin or ghrelin; $;^{141,147}$ one study, intriguingly, found higher levels of ghrelin after sleep restriction in men but not in women, ${ }^{150}$ paralleling some of the data on differences in weight gain in response to experimental sleep restriction. Elevated ghrelin levels may predict an increased food intake during experimental sleep restriction. ${ }^{151}$ Other changes induced by sleep restriction include blunting of the usual nocturnal decline in cortisol levels ${ }^{149,152,153}$ and increases in levels of peptide YY (which acts to inhibit food intake). ${ }^{154}$ Conversely, experimental sleep extension has been carried out, albeit by fewer investigators, and found to reduce leptin and peptide YY levels. ${ }^{155}$ These neuroendocrine alterations may underlie the observed changes in caloric intake which, along with decreased physical activity, appear to promote weight gain in sleep restriction (possibly more in men than in women) despite unchanged or even increased energy expenditure.

\section{Impact on insulin and glucose homeostasis}

Experimental sleep restriction has also been shown in a large number of studies in adults to induce IR (fasting and/or postprandial), with variable impact on insulin secretion. ${ }^{30,153,156,157}$ Endogenous glucose production is increased and impairment of glucose tolerance occurs even in healthy lean adults, especially when combined with circadian disruption. ${ }^{24,153,158}$ The metabolic changes accompanying experimental alterations in sleep duration are thought to be partially mediated by the same neuroendocrine perturbations discussed above in the alterations in sleep duration and obesity section, including higher evening cortisol levels (in some though not all studies) and increased sympathetic nervous system activity and catecholamine production in the sleep debt-condition. ${ }^{152,153,157,159}$ Sleep restriction can also increase free fatty acid (FFA) levels, another contributor to IR, and induce a proinflammatory state by elevating the levels of cytokines, such as interleukin
(IL)-1 $\beta$, IL-6, IL-17, and C-reactive protein (CRP), which can in turn promote IR. ${ }^{158-160}$ The proinflammatory effect of sleep deprivation may be persistent; data from the Whitehall II study showed that each hour decrease in sleep duration per night was associated with higher levels of CRP (8.1\%) and IL-6 (4.5\%) averaged across measures both at baseline and after an average of 5 years of follow-up. ${ }^{161}$ Decreased levels of glucagon-like peptide-1, which augments glucoseinduced insulin secretion in response to ingestion of nutrients, were seen in experimentally sleep-restricted women ${ }^{150}$ and could be one of the mechanisms by which sleep restriction increases IR. Interestingly, the metabolic alterations of sleep deprivation are not just seen at the systemic level-compared to normal sleep conditions, partial sleep deprivation leads to impairment of phosphorylation in adipocytes of the serine/ threonine kinase Akt (part of the insulin signaling pathway), indicating insulin resistance at the cellular level. ${ }^{162}$ Recent findings suggest that experimental sleep restriction can lead to tissue-specific epigenetic changes in the expression of circadian clock genes and the transcriptome affecting a wide variety of biological processes, including chromatin modification, gene expression regulation, macromolecular metabolism, and inflammatory, immune, and stress responses, providing yet another link between sleep deprivation and tissue responses. ${ }^{163,164}$

If sleep restriction exerts a causal impact on insulin and glucose homeostasis, then sleep extension should exert the opposite impact. Fewer experimental sleep extension studies have been conducted, but the results of those few studies that have been carried out are encouraging. Experiment sleep extension has been found to improve insulin sensitivity and reduce cortisol levels..$^{155,165,166}$ The experimental sleep restriction and extension data point to the causal impact exerted by acute changes in sleep duration on IR and glycemia and may help explain the associations between insufficient sleep duration and T2DM risk in epidemiological studies.

\section{Hypertension}

Experimental sleep restriction in adults raises blood pressure, especially nocturnal blood pressure, likely related to blunting of the nocturnal blood pressure dipping that normally occurs during sleep. ${ }^{167-170}$ Possible mechanisms include elevations in cortisol and increased catecholamine production (as discussed above in the sections on alterations in sleep duration and obesity, insulin resistance and glucose homeostasis) leading to an increased sympathetic nervous system activity systemically, in combination with a decreased 
parasympathetic activity, an increased muscle sympathetic nerve activity and resetting of the arterial baroreflex (with decreased sensitivity), an induced endothelial dysfunction, and impaired vasodilatation. ${ }^{167,168,171-173}$ Acute sleep restriction also reduces heart rate variability. ${ }^{174}$ More recently, acute sleep restriction has been found to promote arterial stiffness as measured by pulse wave velocity (PWV) (a marker of CVD risk) and to lead to subclinical left ventricular diastolic functional changes, with increases seen in myocardial performance index, isovolumetric relaxation time, and deceleration time values. ${ }^{175,176}$

\section{Dyslipidemia}

The impact of acute sleep restriction on serum lipids has been somewhat inconsistent across studies, with one study showing no impact of experimental sleep restriction on lipids in healthy normal-weight adults aged 30-45 years (in the setting of controlled caloric intake), ${ }^{177}$ one study showing improvement in triglyceride levels in normal-weight young adult men following sleep restriction, ${ }^{178}$ and another study showing increase in total cholesterol and LDL levels (as well as neutrophil levels) in healthy postmenopausal women receiving hormone replacement therapy following sleep restriction, ${ }^{179}$ while yet another study of normal-weight young men (aged 22-29 years) showed a postsleep restriction rise in the levels of myeloperoxidasemodified LDL, ${ }^{180}$ a substance that accumulates in macrophages to form foam cells and is thought to be atherogenic. ${ }^{181}$ Very recently, an experimental partial sleep restriction study of 14 subjects vs seven controls found that sleep restriction decreased the expression of genes encoding cholesterol transporters and increased expression in pathways involved in inflammatory responses, although circulating LDL decreased rather than increased in the sleep-restricted subjects. ${ }^{182}$ Metabolomic analyses in 2,739 adults also found that those reporting chronically insufficient sleep had lower circulating large LDL. ${ }^{182}$ These findings suggest that while the impact on lipids is not necessarily apparent in acute sleep restriction, prolonged or chronic sleep deprivation can modify inflammatory and cholesterol pathways at the level of gene expression and serum lipoproteins, inducing changes that increase cardiometabolic risk.

Notwithstanding the limitations inherent to short-term rather than prolonged manipulation of sleep, the experimental sleep restriction and the few experimental sleep extension studies discussed above in the experimental evidence/ pathophysiology sections examining sleep duration impact on obesity, insulin resistance and T2DM risk confirm the causal role of sleep restriction (though not the risk of long sleep) in the adverse metabolic changes, which predispose to the MetS and CVD.

\section{Children and adolescents}

Compared with the relatively more abundant body of adult data, very few experimental sleep restriction studies examining metabolic sequelae have been performed in school-age children, preadolescents, or even adolescents. The few published studies are discussed in the sections below are discussed in the sections below.

\section{Prepubertal children}

A recent study of mild experimental sleep restriction in 25 typically developing 8-12-year-old children found that attention-deficit hyperactivity symptoms increased, but there was no difference in overall activity levels, though the variability in activity increased. ${ }^{183} \mathrm{~A}$ crossover sleep restriction/ sleep extension study by $1.5 \mathrm{~h} / \mathrm{night} \times 1$ week each in a cohort of $378-11$-year-old children found that leptin levels were lower and children consumed $\sim 134 \mathrm{kcal} / \mathrm{d}$ less and weighed $0.22 \mathrm{~kg}$ less in the sleep-extended condition than in the sleeprestricted condition. ${ }^{184}$

\section{Adolescents}

Adolescents with shorter actigraphically measured sleep duration ( $<8$ hours) consume more calories than their longersleeping peers, and a higher percentage of calories derives from fat and a lower percentage from carbohydrates. ${ }^{185}$ Beebe et al ${ }^{186}$ restricted 41 typically developing adolescents, aged 14-16 years, to sleeping $6.5 \mathrm{~h} / \mathrm{night}$ for five nights vs sleeping $10 \mathrm{~h} /$ night and found that their diets had a higher glycemic index and glycemic load and a trend toward more calories and carbohydrates, with no differences in fat or protein consumption. Another crossover sleep restriction/sleep extension study in 31 adolescents similarly found that after mild $(6.5 \mathrm{~h} /$ night) experimental sleep restriction, the participants found sweet foods and desserts were more appealing, although their subjective hunger ratings did not change. ${ }^{187} \mathrm{~A}$ pilot study of nine obese adolescents found that 1 hour of sleep restriction per night for 1 week mildly raised insulin and glucose levels and, unlike the adult data, led to a higher rather than lower leptin levels; participants also gained a mean of $0.8 \mathrm{~kg} .{ }^{188} \mathrm{In} \mathrm{a}$ more intensive sleep restriction study, 21 lean adolescent boys were restricted to sleeping 4 hours for three nights, leading to a significant increase in fasting and nonfasting insulin levels, but without any changes in fasting or postchallenge glucose levels, awakening cortisol response, daytime or 24-hour sympathovagal balance, and glucagon or norepinephrine levels; 24-hour epinephrine levels were lower in the sleep-restricted stage vs sleep recovery stage. ${ }^{189}$ These limited studies compellingly reinforce the need for more experimental data in children prior to drawing any conclusions. 


\section{Obstructive sleep apnea and cardiometabolic risk Obstructive sleep apnea}

Obstructive sleep apnea (OSA) is a very common condition among obese adults and children. ${ }^{190,191}$ OSA consists of repetitive upper airway collapse during sleep, ${ }^{192}$ leading to recurrent oxyhemoglobin desaturation, sleep fragmentation, and hypercapnia. ${ }^{193} \mathrm{~A}$ wide body of literature in adults now exists showing that OSA contributes to cardiometabolic risk independently of or additively to obesity-IR, ${ }^{194,195}$ the MetS (presence or components thereof), ${ }^{196,197}$ incident T2DM risk, ${ }^{198,199}$ poor glycemic control in $\mathrm{T} 2 \mathrm{DM},{ }^{200-202}$ incident $\mathrm{CVD},{ }^{203}$ stroke, ${ }^{204}$ and cardiovascular ${ }^{205}$ and all-cause ${ }^{206}$ mortality. However, the differences between pediatric and adult OSA showcase the fact that these conditions are related but not identical disorders, with possible differences in attendant metabolic risk. Pediatric data about the association between OSA and metabolic risk is more contradictory. In addition to epidemiological data, numerous interventional studies, with the gold standard continuous positive airway pressure (CPAP) in adults and adenotonsillectomy (T\&A) in children, have now been performed to examine causality. These data are discussed in the following paragraphs, following some background information about OSA.

\section{OSA frequency across the lifespan, sex differences, and the impact of androgens}

The diagnostic criteria for OSA differ between adults and children. In adults, OSA is frequently defined as having an apnea hypopnea index (AHI; number of events of decreased and/or complete cessation of airflow) or a respiratory disturbance index (RDI) $>5$ events/h total sleep time (TST), ${ }^{207}$ while in children, the AHI cutoff for OSA has been variably defined $>1$ events $/ \mathrm{h},>1.5$ events $/ \mathrm{h}$, or $>2$ events $/ \mathrm{h}$ TST, but OSA is considered mild if AHI is $<5$ events/h TST. ${ }^{208}$ This difference further reinforces the motto that "children are not small adults".

The prevalence of OSA across the lifespan differs among the sexes. In prepubertal children, OSA prevalence is nearly equal among the sexes, ${ }^{209}$ while in adolescence, a malepredominant pattern becomes manifest. ${ }^{210}$ In adults, OSA is considerably more common in men than in premenopausal women, and OSA in women is more likely to be milder. ${ }^{203}$ However, the prevalence and severity of OSA in women rises strikingly after menopause. ${ }^{211}$ These sex differences, which emerge in puberty and which are partially though not fully negated after menopause, ${ }^{212}$ may be in part mediated by the higher androgen levels in men and consequent effects on both airway structure and airway rigidity - testosterone increases upper airway collapsibility. ${ }^{213}$

For all of these reasons, it is important to examine the metabolic effects of OSA separately in prepubertal children vs adolescents and separately in adult men vs premenopausal women.

\section{Epidemiological data}

\section{Adults}

OSA and obesity

OSA prevalence is estimated to be $\sim 26 \%$ in all US adults aged $30-70$ years and as high as $45 \%$ in obese adults. ${ }^{214,215}$ Conversely, $>70 \%$ of adults with OSA are obese. ${ }^{216}$ Thus, obesity, in particular central obesity, clearly predisposes to the development of OSA. ${ }^{203,217}$ Numerous studies have shown the development or worsening of OSA with increasing weight and, conversely, substantial improvement in OSA with weight reduction. Supporting the causal role of obesity in OSA, weight loss (especially in the context of bariatric surgery) ameliorates OSA, though such surgical interventions do not necessarily lead to full OSA resolution. ${ }^{218}$ However, the relationship between OSA and obesity is not unidirectional - OSA itself may cause further weight gain and predispose to visceral adiposity. ${ }^{215,219,220} \mathrm{~A}$ randomized controlled trial testing the impact of CPAP vs sham CPAP on weight in 1,105 adults with OSA found that those treated with CPAP gained an average of $0.35 \pm 5.01 \mathrm{~kg}$, with the degree of weight gain proportional to the degree of CPAP adherence, while those treated with sham CPAP lost a mean of $0.70 \pm 4.03 \mathrm{~kg} .{ }^{221}$ The weight increase may be due to a treatment-related decrease in sleep-related energy expenditure, which is typically elevated in OSA. ${ }^{222}$

\section{OSA associations with the MetS}

Having OSA increases risk of having the MetS and its various components; ${ }^{196,197}$ with increasing OSA severity, the number of MetS features increases independently of BMI. ${ }^{223}$

\section{OSA and insulin sensitivity, beta cell function, and T2DM}

An extensive body of literature has now demonstrated that OSA is associated with an increased IR in adults independently of obesity. ${ }^{194-196,223,224}$ OSA has also been found to associate with impairment of beta cell function (having a lower disposition index on intravenous glucose tolerance test). ${ }^{225}$ Similarly, the Sleep Heart Health Study, a multicenter cohort study examining the cardiovascular and other consequences of sleep-disordered breathing, also found that increasing OSA 
severity associated with incrementally greater OR of glucose intolerance. ${ }^{196}$ These data suggest that OSA may increase the risk of T2DM incidence; indeed, several cross-sectional studies have reported that OSA associates with increased OR of having T2DM independently of obesity. ${ }^{26,227}$ The Wisconsin Sleep Cohort Study (a longitudinal study of 1,387 adult participants followed for more than two decades) found a significant association between moderate-severe OSA presence and OR of T2DM even adjusting for obesity (OR 2.3). ${ }^{228}$ Several additional longitudinal studies have also shown that having OSA at baseline increases the likelihood of incident T2DM over time independently of other risk factors, ${ }^{224,228-230}$ an effect found to be more notable in women than in men in at least one study. ${ }^{231}$ The Sleep Heart Health Study also found that the association between OSA severity and likelihood of having T2DM was more prominent in younger adults rather than in older adults, ${ }^{203}$ possibly because other T2DM risk factors may play a larger role in diabetes prevalence in the latter. A recent populationbased study examining the OSA-T2DM association in 8,678 adults with OSA followed for a mean of 67 months found a cumulative T2DM 5-year incidence rate of $9.1 \%(95 \% \mathrm{CI}$ $8.4 \%-9.8 \%)$ over 5 years in the cohort $(n=1,017)$, with a $30 \%$ higher risk in those with severe OSA (AHI $>30$ events/h TST) vs those without OSA (AHI $<5$ events/h TST). ${ }^{232}$ Additionally, those with T2DM and OSA usually had poorer glycemic control than those without OSA. ${ }^{200-202}$

The converse relationship between OSA and T2DM has also been observed - ie, the prevalence of OSA among adults with known T2DM ranges between 58 and $86 \%,{ }^{233}$ substantially higher than recent estimates from a communitybased cohort without T2DM of $17 \%$ in women and $34 \%$ in men. ${ }^{214}$ As these two conditions are so frequently comorbid, the International Diabetes Federation recommends that a patient who presents with one condition should be screened for the other. ${ }^{234}$

Despite the epidemiological data described earlier in the Epidemiology of OSA segment of this review, the metabolic, the metabolic impact of OSA treatment is somewhat variable. CPAP therapy in adults has been shown to improve insulin sensitivity in many studies, ${ }^{235,236}$ although some studies show no impact on insulin sensitivity, ${ }^{237}$ and one recent study even found an increase in IR following initiation of CPAP treatment (which appeared to be primarily due to CPAP-associated weight gain). ${ }^{238}$ Recently, a randomized, parallel-group 6-month trial of CPAP, weight loss, or both CPAP and weight loss in obese adults with OSA found that IR decreased only in response to weight loss; there was no independent impact of CPAP therapy on insulin sensitivity. ${ }^{237}$
Data regarding the impact of CPAP therapy on lowering blood glucose levels and $\mathrm{HbA} 1 \mathrm{C}$ have also been somewhat unpredictable, ${ }^{239,240}$ though a recent study found lowering of $\mathrm{HbA} 1 \mathrm{C}$ in adults with T2DM and OSA who received CPAP therapy when compared to those who did not receive CPAP therapy. ${ }^{241}$

In summary, although epidemiological data associating OSA with IR and T2DM risk in adults are substantially and relatively consistent, the impact of OSA treatment on insulin sensitivity and glycemia in adults is more contradictory, and it appears that the CPAP-associated weight gain may confound the impact of treatment on insulin and glucose metabolism.

\section{Hypertension}

A number of cross-sectional and longitudinal studies have found that OSA associates with an increased risk of hypertension (both systolic and diastolic) independently of BMI. ${ }^{242-245}$ The Wisconsin Sleep Cohort Study found a linear relationship between 24-hour blood pressure and AHI, independent of potential confounders, including the degree of obesity. ${ }^{246}$ However, at least one study found no association between OSA and hypertension independent of other risk factors. ${ }^{247}$ One of the ways in which OSA may affect blood pressure may relate to a blunting of the normal nocturnal blood pressure dipping, which can be seen in adults with OSA who are otherwise normotensive as well as in those with OSA and frank hypertension. ${ }^{248-250}$ The lack of blood pressure dipping does not seem to be solely mediated by poor sleep quality ${ }^{250}$ but appears to preferentially relate to the RDI, a measure of respiratory disturbance in sleep, or more specifically to the intermittent hypoxia $(\mathrm{IH})$ that results from the respiratory disturbances. ${ }^{248}$

As might be expected given the abovementioned data, there is a high prevalence of OSA in adults with drug-resistant hypertension, with prevalence being reported as high as $83 \%{ }^{251}$ Indeed, OSA has been deemed the most common cause of secondary hypertension in adults with drug-resistant hypertension. ${ }^{252}$

A number of studies have examined the impact of CPAP therapy on blood pressure (BP); several meta-analyses concluded that CPAP had significant but modest effects on blood pressure, with more significant improvements seen in those with more severe OSA. ${ }^{253-255}$ CPAP therapy for 12 weeks in adults with drug-resistant hypertension and OSA led to a significant decline in 24-hour mean BP and diastolic BP and to improved nocturnal BP pattern. ${ }^{256}$ Interestingly recent meta-analysis found that intraoral appliance devices (which are generally better tolerated than CPAP) may be as effective in improving $\mathrm{BP}$ in adults with OSA. ${ }^{257}$ 
These data suggest that adults with OSA should be regularly screened for hypertension and, conversely, that adults with drug-resistant hypertension should be screened for OSA.

\section{Dyslipidemia}

OSA is associated with an increased risk of atherogenic dyslipidemia in adults. A number of cross-sectional studies in different populations have found higher total cholesterol and LDL cholesterol levels, higher triglycerides levels, lower HDL levels, or all of the above in adults with vs without OSA..$^{258-262}$ The Sleep Heart Health Study found an inverse association between the RDI and HDL levels in all participants and a positive association between the RDI and triglycerides in younger men and women only. ${ }^{203}$ There is some evidence that both sleep fragmentation and IH contribute to dyslipidemia: a recent cross-sectional study in the People's Republic of China found that the associations between OSA and high LDL levels were driven by sleep fragmentation, ${ }^{259}$ while two other studies have recently found that the AHI associates with dyslipidemia. ${ }^{260,263}$

\section{MetS}

Multiple cross-sectional studies have reported an epidemiological association between OSA and the MetS ${ }^{261,264}$ and that greater OSA severity increases the OR of having the MetS. ${ }^{265}$ These associations have since been found in a number of other cohorts. ${ }^{266}$ The frequency of MetS in adults with OSA is quite high, with estimates ranging from $43 \%$ in those with mild-moderate OSA to $81 \%$ in those patients with severe OSA. ${ }^{267}$ Conversely, OSA is quite frequent in those patients with MetS: in a cohort of 228 obese adults, the frequency of OSA in the MetS was $60 \% .{ }^{197}$

\section{Atherosclerosis, arterial stiffness, CVD, stroke, and cardiovascular and all-cause mortality}

OSA has been associated with an increased risk of atherosclerosis, independently of the degree of obesity. Several adult studies have now identified increased carotid intima media thickness (cIMT; a surrogate measure of atherosclerosis) in adults with OSA, and duration of hypoxemia has been strongly associated with cIMT. ${ }^{268}$ Even in the context of existing dyslipidemia, having OSA was associated with an increased risk of the presence of atherosclerosis. ${ }^{263}$

OSA is also associated with an increased arterial stiffness, a consequence of decreased vascular compliance which occurs as a result of a combination of structural changes in arterial walls and endothelial dysfunction. ${ }^{269-271}$
Given the associations between OSA and a multitude of risk factors, it should come as no surprise that OSA also increases the risk of cardiovascular and cerebrovascular diseases. The Sleep Heart Health study found that OSA is a significant, independent risk factor for $\mathrm{CHD}$ and heart failure in men aged 40-70 years but not in older men and women, ${ }^{272}$ that significant increases in all-cause mortality and CHD-related mortality are attributable to OSA (especially in men aged 40-70 years), ${ }^{273}$ and that OSA (specifically, obstructive AHI) associated significantly with incident ischemic stroke; the increased stroke risk in men was seen even in those with very mild OSA (AHI 5 events/h sleep and wake-up), while in women, an increased risk of incident stroke was seen only in those with fairly severe OSA (AHI >25 events/h TST). ${ }^{274}$ The hypoxemia associated with OSA also increases the risk of sudden cardiac death. ${ }^{275}$

In summary, epidemiological evidence in adults shows that OSA increases the risk of cardiometabolic morbidities in the context of obesity, but that it also contributes independently toward the risk of hypertension, IR, and T2DM, variably to dyslipidemia, overt MetS, arterial stiffness, atherosclerosis, incident CVD, stroke risk, and CVD-related mortality and all-cause mortality.

\section{Children and adolescents}

Pediatric OSA appears to have two different phenotypic variants, which we have previously termed as OSA Type I and OSA Type II. ${ }^{276}$ OSA Type I, which predominates in younger children and affects males and females near-equally, relates predominantly to the presence of lymphadenoidal hypertrophy leading to airway obstruction rather than to obesity. In contrast, OSA Type II predominates in obese prepubertal children, adolescents, and adults, is seen much more commonly in males than in females, primarily develops in the context of obesity, and bears a greater resemblance to the OSA clinical phenotype seen in adults, even though lymphadenoidal hypertrophy is still an important part of the pathophysiology of OSA. ${ }^{277}$ A recent publication from the Cleveland Children's Sleep and Health Study found that a majority of cases of childhood OSA remit and that most cases of OSA in adolescents represent incident cases, supporting the hypothesis of phenotypically different childhood OSA variants. ${ }^{278}$ It is possible that OSA type may confer a different underlying predisposition to metabolic sequelae.

\section{Pediatric OSA and obesity}

As in adults, obese children are at increased risk of OSA, ${ }^{279}$ with higher risk in obese African American vs Caucasian children; ${ }^{280,281}$ a recent community-based study of OSA 
prevalence in obese Spanish children aged 3-14 years found a prevalence of $21.5 \%,{ }^{282}$ considerably higher than the estimate in all children of $7.5 \%$. However, the obesity-related increased risk of OSA may differ in prepubertal children vs adolescents. ${ }^{283}$ Also, several studies have found that obesity increases OSA risk significantly more in adolescents compared to younger children, ${ }^{284,285}$ that having OSA may be associated with visceral adiposity in adolescents, ${ }^{283}$ and that bariatric surgery in extremely obese adolescents leads to significant improvement in sleep-disordered breathing. ${ }^{286}$

\section{IR and glucose metabolism}

In opposition to the adult data, the relationship between OSA and IR in children is more inconsistent. Several pediatric studies have shown no association between OSA and IR or MetS risk, ${ }^{287-294}$ while others found associations between the presence or severity of OSA and IR and between OSA components (RDI, mean oxyhemoglobin saturation, and duration of hypoxemia) and insulin sensitivity or glycemia independent of BMI. ${ }^{291,293-296}$ Another study did not find an association between OSA and IR overall but did report that in children with OSA, there was an association between hypoxemia and IR. ${ }^{297}$ Yet another study noted an association between OSA and IR only in obese pubertal children (ie, adolescents) and not in nonobese or prepubertal children. ${ }^{295}$ In the largest study published to date $(n=459)$ examining these associations in children and preadolescents, we found that sleep fragmentation was significantly associated with IR and that in the context of obesity, OSA was associated with an increased IR. ${ }^{126}$ Treatment of OSA via adenotonsillectomy has been found to improve IR in some but not all studies; however, the majority of treatment studies have focused on prepubertal children, in whom IR is seldom manifesting at baseline. . $89,298,299^{2}$

OSA has been associated with higher fasting glucose levels in adolescents. ${ }^{300}$ The data on OSA and T2DM in children are quite scarce, with only one study having examined this particular question to date: Shalitin et al compared the rate of OSA among adolescents and young adults with obesity, impaired glucose tolerance, and T2DM and found frequencies of OSA (defined as AHI > 5 events/h TST) of $18 \%, 25 \%$, and $46 \%$ respectively, although the differences did not achieve statistical significance due to the small sample size. ${ }^{301}$ Further studies are needed to assess the association between OSA and risk of T2DM in the pediatric population.

\section{Hypertension}

Many (though not all ${ }^{302}$ ) studies have shown that OSA associates with elevated daytime and nocturnal BP in children independently of obesity, ${ }^{303,304}$ and the community-based Tucson Children's Assessment of Sleep Apnea found that in preadolescents, systolic BP and diastolic BP (DBP) were associated with poor sleep quality and the RDI and, for DBP only, obesity. ${ }^{305}$ Even in the absence of OSA, poor sleep quality in adolescents associates with higher blood pressure and prehypertension. ${ }^{112}$ OSA has also been shown to be an independent predictor of nocturnal hypertension in children, ${ }^{306}$ which relates to oxyhemoglobin desaturation. ${ }^{304}$ Diastolic BP may be more impacted than systolic BP. ${ }^{307}$ Oxyhemoglobin desaturation has also been shown to correlate with a decreased nocturnal BP dipping. ${ }^{303}$

Treatment of OSA with T\&A has been shown to improve BP in children in some but not all studies; ${ }^{308,309}$ the multicenter randomized study on adenotonsillectomy for OSA in children aged 5-9 years (Childhood Adenotonsillectomy Trial) did not find any improvements in BP after T\&A, ${ }^{310}$ although it should be stressed that these were prepubertal children with relatively mild OSA. Thus, the data on OSA and hypertension in children are somewhat mixed, and further studies are needed.

\section{Dyslipidemia}

Children with OSA are more likely to have abnormal lipids than children without OSA in some studies, ${ }^{311,312}$ though other studies have found that obesity rather than OSA was the primary mediator of dyslipidemia. ${ }^{288}$ The impact of T\&A on lipids in children has been variable - some studies have shown increased HDL, ${ }^{298}$ lower both LDL and apolipoprotein $\mathrm{B},{ }^{289}$ and/or total cholesterol, ${ }^{299}$ while others have shown no impact of T\&A on lipid levels. ${ }^{313}$

\section{MetS}

OSA has been associated with the MetS in children and even more strongly in adolescents: ${ }^{314}$ in adolescents, the MetS was seen in $16 \%$ of those without OSA and in $59 \%$ of those with OSA, a 6.5-fold increased risk after adjusting for confounders, and similarly, that $25 \%$ of those with OSA had the MetS. ${ }^{293}$ This study also found that the frequency of respiratory events, the degree of oxyhemoglobin saturation, and sleep efficiency were all associated with an increased MetS risk. A more recent case-control study of obese children found that OSA was more common in those with vs without the MetS. ${ }^{315}$ A study of 104 obese children and adolescents, of whom 58\% were prepubertal, found an association between oxyhemoglobin desaturation measures and MetS risk. ${ }^{314} \mathrm{~A}$ recent meta-analysis found that OSA associated with a 2.3fold increased RR of the MetS. ${ }^{316}$ However, not all studies 
are consistent: at least one study in obese prepubertal as well as pubertal children found no association between obesity and the MetS. ${ }^{317}$ Finally, no studies to our knowledge have examined the impact of treating OSA on MetS frequency or risk in children. Most likely because of the long nature of follow-up that would be required. However, the cross-sectional data suggest an interaction between pediatric MetS and OSA, particularly in adolescents, in which one increases the risk for the other, and suggest that in adolescents diagnosed with either the MetS or OSA, screening for the other may be warranted.

\section{Endothelial dysfunction, atherosclerosis, and arterial stiffness}

While adult CVD likely has its roots in childhood, ${ }^{318}$ overt cardiovascular or cerebrovascular disease is extremely rare during early life. However, antecedents of CVD, such as endothelial dysfunction, subclinical atherosclerosis, and arterial stiffness, have been reported in childhood. ${ }^{319-323}$ Similar to adults, OSA is associated with all such predisposing risk factors, but in children, the relationships are not as overtly established. Our group has published extensively on the obesity-independent association between OSA in childhood and endothelial dysfunction, a risk factor for atherogenesis: blunting of postocclusive hyperemia has been reported in both nonobese and obese school-age children with OSA. ${ }^{324-326}$ Pediatric data regarding endothelial dysfunction have been gathered in prepubertal school-age children; no study of which we are aware has examined endothelial dysfunction in association with OSA in adolescents. Early arterial alterations with impaired flow-mediated dilation have also been reported in children with OSA and severe obesity. ${ }^{327}$

The data about OSA and reversible endothelial dysfunction would seem to support a role for pediatric OSA as a contributor to the pediatric roots of adult CVD; however, the more overt measures of CVD (atherosclerosis and arterial stiffness), which are associated with OSA in adults, do not necessarily exhibit the same associations in children. Very few pediatric studies have examined the associations between OSA and these more overt cardiovascular risk factors, with somewhat contradictory results. Two pediatric studies (including a mixed child-adolescent cohort and an adolescent-only cohort) found no association between OSA and cIMT as a surrogate measure of atherosclerosis independently of obesity, ${ }^{328,329}$ but a more recent study of 40 children with adenotonsillar hypertrophy aged 5-10 years and 36 age- and BMI-matched controls found a higher cIMT in the adenotonsillar hypertrophy group. ${ }^{330}$ One study of 30 children and adolescents with primary snoring vs
BMI-, age-, and sex-matched controls found a greater degree of peripheral arterial stiffness as measured by brachial-ankle PWV in those with primary snoring, ${ }^{329}$ but two subsequent studies found no association between OSA and central arterial stiffness and carotid-femoral PWV. ${ }^{330,331}$ Finally, one study of preschool-aged and school-aged children with OSA found a reduced left ventricular ejection fraction (although no clinical signs of heart failure) and that in some of the subjects, treatment of OSA improved left ventricular ejection fraction. ${ }^{332}$

These data illustrate that while OSA in children may be associated with early measures of CVD risk, such as obesity, IR, hypertension, dyslipidemia, the MetS, and endothelial dysfunction, which are variably reversible upon treatment of OSA (generally less reversible in the obese), there is not necessarily a consistent progression to an association between OSA and vascular changes prior to adulthood. Future longitudinal and interventional studies are needed to examine these associations in larger pediatric cohorts, separating out children and adolescents.

\section{Experimental data and pathophysiology}

\section{Adults}

OSA has been associated with sympathetic/adrenomedullary activation as well as (more variably) with activation of the hypothalamic-pituitary-adrenal (HPA) axis. ${ }^{333,334}$ OSA is also a well-recognized proinflammatory state, accompanied by increased levels of CRP and other inflammatory cytokines. ${ }^{335-338}$ In addition, activation of macrophages is seen in OSA; these activated macrophages in turn reduce the activity of peroxisome proliferator-activated receptor-gamma (a negative regulator of inflammation and regulator of lipid and glucose metabolism) in alveolar macrophages even in the absence of overt lung disease, to a greater degree than seen in obesity alone. ${ }^{339}$ There is also an improvement seen in a number of inflammatory factors upon OSA treatment with CPAP. ${ }^{340,341}$

As described earlier in the OSA epidemiology section of this review, OSA is also associated with a number of cardiometabolic sequelae independently of obesity in adults, to which the sympathetic activation, HPA axis activation, and inflammation variably contribute.

\section{Obesity}

It is well-recognized that obesity predisposes to OSA development, and in fact, specific fat depots (upper airway, tongue, and abdominal adipose deposition) appear to predispose to OSA. ${ }^{342-344}$ However, OSA may also predispose to obesity due to daytime somnolence, decreased activity, 
and decreased sleep duration, as well as due to neurohumoral changes seen in OSA, including elevation in the orexigenic hormones ghrelin and orexin and suppression of the anorexigenic hormone leptin (seen in many though not all studies of adults with OSA). ${ }^{343,345-347}$ As discussed in the OSA epidemiology section above, although there is a strong association between OSA and obesity, treatment of OSA in adults may result in weight gain, possibly due to a decrease in resting energy expenditure (which has been found to be proportional to the decrease in AHI and in urinary catecholamine production and also to CPAP adherence),${ }^{348}$ suggesting that decreased sympathetic activation promoted the weight gain with CPAP therapy. However, CPAP-induced weight gain in adults with OSA may not be due to fat mass gain: lean body mass has been found to increase in both sexes with CPAP treatment, which in the male participants may have been mediated by increased growth hormone levels, as levels of insulin-like growth factor-1 (produced in response to growth hormone) increased in the men treated with OSA. ${ }^{349}$ Regardless of effect on total body weight, OSA treatment with CPAP may lead to a reduction in visceral fat even in the absence of significant weight loss. ${ }^{220}$ Treatment of OSA may also induce neurohumoral changes, which can predispose to changes in weight, such as lower leptin and/or ghrelin levels. ${ }^{220,238}$ However, whether these findings translate to behavioral differences is uncertain; a recent study found no change in diet (or in physical activity patterns) in adults with OSA treated with CPAP. ${ }^{350}$

\section{OSA and the MetS}

When examining the pathophysiology of the association of OSA with the MetS, this process essentially entails examining the impact of OSA on MetS components: IR, dysglycemia, hypertension, and dyslipidemia.

\section{OSA, IR, and T2DM}

Classically, OSA is thought to adversely impact glucose metabolism via a combination of IH and sleep fragmentation..$^{25,351,352}$ Potential underlying mechanisms for the OSA-IR association include onset and propagation of oxidative stress and inflammation with the elevation of inflammatory mediators, such as CRP and proinflammatory cytokines, increased corticosteroid levels, sympathetic activation, catecholamine elevations, and/or alterations in adipokines. ${ }^{353-356}$ Some of the putative relationships between OSA and IR (as well as its sequelae) are illustrated in Figure 1.

Evidence for causality is supported by an experimental study in which hypoxia was induced in healthy adult volunteers by decreasing oxygen saturation to $75 \%$ (vs $96 \%$ in control subjects) for 30 minutes while undergoing a euglycemic clamp; the acute hypoxia induced an increase in plasma epinephrine concentration, heart rate, and symptoms of anxiety - signs of sympathetic activation - and also a decreased rate of dextrose infusion, suggesting acute IR. ${ }^{357}$ Also supporting the causality of the link between OSA and IR, several studies have shown that CPAP therapy improves $\mathrm{IR},{ }^{358}$ including IR as measured by the gold standard hyper-

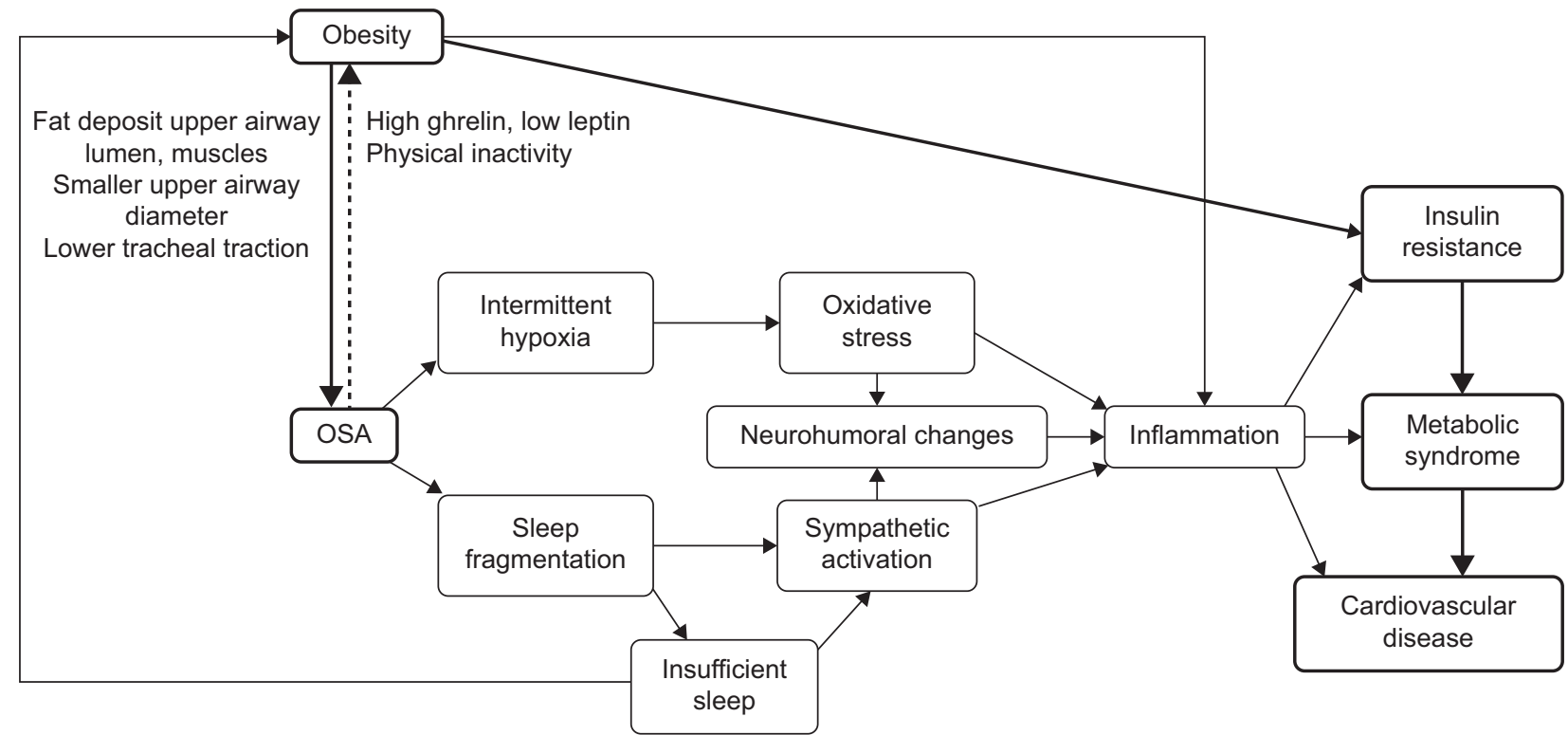

Figure I Putative relationships between OSA and obesity, insulin resistance, the metabolic syndrome, and cardiovascular disease. Abbreviation: OSA, obstructive sleep apnea. 
insulinemic-euglycemic clamp, ${ }^{235}$ although the improvement in IR may take several months to manifest. ${ }^{235}$ The improvement in insulin sensitivity and glycemia may be mediated by changes in plasma leptin, ${ }^{200}$ adiponectin (an insulinsensitizing adipokine), ${ }^{359}$ or by improvements in sympathetic activation and/or HPA activation as as described earlier in the OSA epidemiology section.

As discussed in the OSA epidemiology section above, results of studies examining the impact of CPAP therapy on glycemia and T2DM in adults are somewhat contradictory: while many studies show improvement in $\mathrm{HbA} 1 \mathrm{C}$ and in postchallenge glucose levels in adults with OSA after CPAP therapy, some show no effect. ${ }^{199,200,240,360-362}$ The impact of OSA treatment on glycemia may relate to the degree of underlying metabolic derangement, as a recent study found no improvement in $\mathrm{HbA} 1 \mathrm{C}$ following CPAP therapy in 298 adults with relatively well-controlled T2DM (HbA1C $<8.5 \%) .{ }^{363}$ Some of the differences in study results may also be related to the adherence to CPAP therapy: suboptimal adherence ( $<4 \mathrm{~h} /$ night) may not be sufficient to improve glycemia, as it would not sufficiently impact the AHI in rapid eye movement sleep, which is an independent predictor of $\mathrm{HbA} 1 \mathrm{C}$ in adults with T2DM. ${ }^{201}$

\section{Hypertension}

The connection between OSA and hypertension has a number of potential mediators. OSA is well-known to lead to chronic IH, which can be severe, and to sympathetic nervous system activation, with elevations in catecholamines and increased sympathetic nerve activity as measured by microneurography. ${ }^{222,364,365}$ Sleep fragmentation with recurring overnight arousals is also associated with pulsatile and increased cortisol release. ${ }^{333}$ Nocturnal IH can also be associated with a disruption of the autonomic and hemodynamic changes seen during normal sleep, ${ }^{366}$ including increased sympathetic activity in peripheral blood vessels leading to vasoconstriction and acute increases in blood pressure. ${ }^{367}$ The OSA-hypertension link may also be mediated in part by the renin-angiotensin-aldosterone axis; primary hyperaldosteronism may be more common in adults with OSA and hypertension. ${ }^{368}$ The causality of the association between hypoxia and blood pressure is supported by experimental studies in human volunteers, which showed that chronic hypoxia induced by altitude changes increases sympathetic activation and norepinephrine levels ${ }^{369}$ and that even an acute 6-hour exposure to IH elevates high blood pressures in normotensive adults, an elevation which was blocked by the type I angiotensin receptor antagonist losartan. ${ }^{370}$
Treatment of OSA with CPAP has been shown to improve $\mathrm{BP},{ }^{255,363,371}$ restore normal nocturnal BP patterns, and prevent nocturnal blood pressure surges in many but not all studies. ${ }^{254,372,373}$ A placebo-controlled CPAP vs sham-CPAP trial found that CPAP was especially effective at improving nocturnal BP in those using CPAP for $>3.5 \mathrm{~h} /$ night and those with more frequent oxyhemoglobin desaturations, ${ }^{374}$ supporting the causal role of hypoxemia in addition to sympathetic activation and the renin-angiotensin-aldosterone axis in causing OSA-related hypertension.

\section{Hyperlipidemia}

OSA-related dyslipidemia is thought to be mediated by chronic IH; evidence from murine models shows that experimental IH leads to hyperlipidemia, upregulation of the expression of genes promoting hepatic lipid synthesis, and in the presence of diet-induced dyslipidemia, chronic IH leads to the development of atherosclerosis. ${ }^{375-378}$

The increased cardiovascular risk of OSA has been attributed, at least in part, to the lipid abnormalities induced by $\mathrm{IH} .{ }^{378}$ The mechanism for the impact of IH on lipids may be due to the IH-mediated increases in gene expression of the hypoxia inducible factor family, generation of reactive oxygen species, stearoyl-coenzyme A desaturase-1, altered lipid peroxidation, and sympathetic system dysfunction. ${ }^{379,380}$ Catecholamines, whose levels are elevated in OSA, modulate the activity of adipocyte hormone-sensitive lipase via their counter-regulatory effects of antagonizing insulin, leading to the lipolysis and consequent breakdown of triglycerides into free fatty acids (FFA) and glycerol, which then will be resynthesized in the liver to form very low density lipoprotein (VLDL). ${ }^{381}$ Supporting this putative mechanism, adults with OSA have elevated levels of FFA; $; 82$ these nocturnal surges in hepatic FFA production in adults with OSA may accelerate CVD progression and concomitant cardiac dysfunction. ${ }^{383}$ Additionally, LDL clearance may be impacted on OSA, so that LDL-B (a LDL form that is more resistant to being cleared from the circulation) can stay in the circulation for an extended period of time, increasing the risk that LDL could be oxidized and subsequently lead to vascular damage. ${ }^{383}$ Finally, acute hypoxia decreases the transcription of lipoprotein lipase and peroxisome proliferator-activated receptor-gamma leading to increased triglyceride levels in mice. ${ }^{384}$ However, the pathophysiology of dyslipidemia is multifactorial, and the connections with OSA do not necessarily translate to treatment effects: several studies have found no impact of CPAP therapy on lipids independent of weight loss..$^{237,385}$ Thus, the ramifications of OSA interactions with lipids in the context of obesity remain to be fully elucidated. 


\section{MetS}

A randomized crossover trial of OSA with CPAP vs sham CPAP was conducted in 86 adults, $87 \%$ of whom had the MetS; CPAP treatment was associated with significant decreases in systolic and diastolic BP, total cholesterol, LDL, triglycerides, and $\mathrm{HbA1C}$, and the MetS resolved in $13 \%$ of patients undergoing CPAP therapy vs $1 \%$ of those undergoing sham therapy ${ }^{386}$ Other studies have shown that CPAP therapy improves the MetS, ${ }^{386}$ likely via the mechanisms discussed earlier for individual MetS components.

\section{OSA and CVD risk}

There may be a number of different routes by which OSA contributes to CVD risk, in addition to the associations with obesity, IR, T2DM, hypertension, dyslipidemia, and the MetS. One such connection may reside in the presence of endothelial dysfunction, a state of impairment of endothelial vasodilatation, which promotes atherogenesis. Several studies have shown that OSA is associated with endothelial dysfunction independently of obesity ${ }^{387,388}$ and that OSA treatment with CPAP improves endothelial function; ${ }^{389,390}$ the beneficial effects of CPAP therapy on endothelial function are quickly reversed if CPAP therapy is withdrawn. ${ }^{391}$ Similarly, as previously discussed, OSA can increase the risk of atherosclerosis as well as lymphocyte activation, ${ }^{392}$ increase circulating endothelial microparticles, and reduce endothelial progenitor cells among other mechanisms. ${ }^{393}$ Long-term CPAP therapy can reverse atherosclerosis. ${ }^{394}$ OSA also increases the risk of arterial stiffness, mediated by hypertension, respiratory events, and desaturation, ${ }^{395}$ suggesting a role for IH in its pathophysiology. CPAP therapy can improve cIMT and PWV, correlating with reductions in urinary catecholamines and in CRP, respectively; these results suggest that sympathetic activation is a significant contributor to the association of OSA with atherosclerosis, while inflammation plays more of a role in arterial stiffness. ${ }^{396}$ Other studies have since shown improvements in arterial stiffness with CPAP therapy independently of age, BMI, and other risk factors, ${ }^{397-399}$ with one study identifying an association with changes in sympathovagal balance (reduced sympathetic activity) but not with CRP. ${ }^{400}$

Thus, OSA increases the risk of incident CVD, ${ }^{401}$ increases the risk of secondary $\mathrm{CV}$ events, ${ }^{402}$ and decreases the OR of survival of cardiovascular and cerebrovascular events; ${ }^{403}$ however, effective CPAP therapy can significantly reduce the OR of incident and secondary CVD and reduce cardiovascular mortality. ${ }^{401,402}$

The preponderance of evidence in adults suggests that OSA is a significant and independent cardiometabolic risk factor operating through a variety of mechanisms related to sympathetic activation, hypoxemia, inflammation, neuroendocrine changes, and endothelial and vascular dysfunction. Although CPAP therapy may be associated with weight gain rather than weight loss, effective OSA treatment with CPAP (only with adequate adherence and if used for least $4 \mathrm{~h} / \mathrm{night}$ ) may reverse some of these adverse cardiometabolic changes caused by OSA.

\section{Children and adolescents}

Studies examining the impact of OSA treatment upon metabolic derangements in children have been somewhat contradictory, with some showing improvements and others showing no effects. One possible explanation for the contradictory findings in the pediatric literature is that the associations between OSA and metabolism change during puberty: the majority of pediatric studies have either focused on prepubertal children or studied a mixture of prepubertal children and adolescents, thereby not allowing for the differential phenotypes to manifest more clearly. As experimental studies inducing hypoxia cannot ethically be performed in children, the majority of pathophysiological data derive from cross-sectional studies and pre-post interventional studies.

\section{Pediatric OSA and obesity}

As noted earlier in the OSA epidemiology section, obesity is strongly associated with the risk of $\mathrm{OSA}^{404}$ (especially in older children and adolescents), due to anatomical changes. However, OSA also predisposes to the worsening of obesity due to daytime sleepiness, decreased physical activity, and neuroendocrine changes, such as resistance to the anorexigenic hormone leptin; ${ }^{405-407}$ data regarding associations between OSA and levels of the orexigenic hormone ghrelin in children are inconsistent. ${ }^{406,407}$ Treatment of OSA (primarily T\&A, but CPAP in one study) may improve leptin and possibly ghrelin levels, although again, data are somewhat contradictory. ${ }^{407}$ However, despite these favorable changes, treatment of OSA in children does not necessarily lead to weight loss; as in adults, a number of studies have reported post-T\&A weight gain in children and adolescents, ${ }^{408,409}$ likely due to a reduction in energy expenditure during sleep as well as other hormonal changes. However, despite the weight gain, treatment of OSA may have favorable metabolic implications.

\section{Pediatric OSA and the MetS}

IR in pediatric OSA associates with systemic inflammation, ${ }^{410}$ oxidative stress, ${ }^{411}$ and (in adolescents but not in prepubertal children) with lower levels of the insulin-sensitizing hormone 
adiponectin. ${ }^{295}$ As in adults, OSA in children leads to sympathetic nervous system activation, increased heart rate variability, and increased catecholamine production, ${ }^{295,355,405,412-414}$ which likely underlie many of the associations between OSA and blood pressure in children. ${ }^{415}$ Oxidative stress in children with OSA relating to IH has been found to increase lipid peroxidation, which can accelerate atherosclerosis. We and others have found that in younger children, the gold standard therapy for OSA, T\&A, has been associated with the modest improvements in lipid profiles, ${ }^{299,416} \mathrm{BP}$ (more in nonobese children than in obese children), ${ }^{417}$ and improved fasting insulin levels and inflammatory biomarkers (including CRP) even in the absence of obesity, suggesting a causal role for OSA. ${ }^{289,298,418-420}$ However, another study found no improvements in blood pressure following $\mathrm{T} \& \mathrm{~A},{ }^{308}$ and a study of Greek children found no metabolic improvements following T\&A. ${ }^{309}$ There are very limited data on the metabolic effects of OSA treatment with CPAP in children; one study of 34 children and adolescents found an improvement in leptin levels but not in insulin levels. ${ }^{313}$

\section{Pediatric OSA and CVD antecedents}

In addition to the pathophysiological associations discussed earlier in the OSA epidemiology section and in the pathophysiology of OSA connections with T2DM, hypertension and the metabolic syndrome, OSA is associated with endothelial dysfunction in children, possibly mediated by reduced circulating endothelial progenitor cells, ${ }^{421}$ alterations in plasma-derived exosomes leading to disruption of the endothelial barrier, ${ }^{422}$ and alterations in exosomal microRNA. ${ }^{422}$ Endothelial dysfunction can deteriorate overnight, ${ }^{423}$ supporting the causal role of sleep-disordered breathing in the genesis of endothelial dysfunction. Treatment data also support a causal role for OSA in endothelial dysfunction in children: the blunting of postocclusive hyperemia in prepubertal children can be reversed 4-6 months after adenotonsillectomy. ${ }^{325}$

In summary, many studies have focused on prepubertal children but have not separated out pubertal from prepubertal states; future studies should be undertaken to focus more specifically on adolescents, who are more metabolically vulnerable to the MetS and related outcomes.

\section{Circadian rhythm and the MetS Circadian rhythm}

Most mammalian metabolic and behavioral processes are regulated by the circadian system, centrally controlled by the suprachiasmatic nucleus ( $\mathrm{SCN}$ ) of the hypothalamus as well as circadian oscillators in peripheral tissues; this system entrains to the 24-hour light/dark cycle but may also adjust its timing to external stimuli, such as light and food. ${ }^{424}$ Circadian rhythms are regulated by core clock genes, such as Clock (circadian locomotor output cycles kaput), Bmal1 (brain and muscle arnt-like protein-1), Cryptochrome (Cryl and Cry2), and Period (Per1, Per2, and Per3), ${ }^{425}$ which function in transcriptional feedback loops. Circadian misalignment refers to the mismatch between circadian rhythms and lifestyle behaviors ${ }^{426}$ and may be caused by factors such as changes in sleep/wake cycles seen in shift workers or lack of light exposure interfering with light/dark cycle entrainment. ${ }^{427}$ The continuum of circadian misalignment includes blindness, shift work, social jet lag, chronotype (a behavioral preference in the timing of sleep or food intake or physiological manifestation of timing of body temperature nadir or hormonal release), and such sleep disorders as Advanced Sleep Phase Syndrome. Circadian misalignment has strong links to obesity, IR, and the MetS, which is briefly discussed here.

\section{Epidemiological data}

\section{Adults}

Epidemiological studies of circadian disruption have been conducted primarily in shift workers and indicate worsening of cardiometabolic function. One study found higher levels of triglycerides and obesity as measured by BMI and lower HDL cholesterol levels among Swedish shift workers when compared to daytime workers; of these, female shift workers more frequently had impaired glucose tolerance. ${ }^{428}$ Higher levels of postprandial glucose, insulin, and triglycerides were noted among British night shift workers when examining food intake schedules that were changed to accommodate work schedules. ${ }^{429}$ A study of Japanese male shift workers showed an increased age-adjusted incidence of T2DM, defined by $\mathrm{HbA} 1 \mathrm{c} \geq 6.1 \%$, in shift workers compared to daytime workers. ${ }^{430}$ Additionally, the Nurses' Health Study II found a positive association between incidence of T2DM and night shift workers; however, this effect was mediated by body weight. ${ }^{431}$ Increased CHD incidence rates in shift workers have also been linked to circadian misalignment. ${ }^{432}$ Furthermore, nonshift work studies specifically focused on chronotype show a positive association between evening chronotype and diagnosis of arterial hypertension, higher weight, and greater waist circumference. ${ }^{433}$ Evening chronotype is also associated with higher HbA1c levels and worsening glycemic control in adults with T2DM. ${ }^{434}$ 


\section{Children and adolescents}

Adolescent population studies assessing for the disruption of glucose metabolism have shown that evening chronotype is associated with a higher BMI, increased meal portion sizes, reduced dietary restraint, and less healthy dietary habits, ${ }^{435-437}$ but studies focused on risk of the MetS have not been done in children and adolescents.

In summary, the abovementioned findings from epidemiological studies suggest that circadian misalignment is associated with increased risks of MetS, T2DM, and CVD in adults. More importantly, the evidence is very scarce and will require much greater attention in the future considering the 24-hour lifestyles that permeate our modern societies.

\section{Experimental data}

\section{Animal models}

Animal and human experimental models have been used to assess the impact of circadian misalignment on metabolic variables. Specifically, rodent studies demonstrate increases in body mass when subjected to work, ${ }^{438}$ feeding, ${ }^{439}$ and light exposure during the biological day (normal rest phase). ${ }^{440}$ Additionally, studies in Clock mutant mice demonstrate the development of hyperglycemia, relative hypoinsulinemia, hyperlipidemia, and obesity due to changes in their diurnal feeding patterns subsequent to circadian disruption. ${ }^{441}$

\section{Adults}

In human adults, a study demonstrated increased glucose and insulin levels in response to a mixed meal given at the same clock time following a 9-hour circadian phase advance when the test meal was preceded by a high-fat but not low-fat meal. ${ }^{442}$ Furthermore, triglyceride levels were found to be elevated after the mixed meal following a 9-hour phase advance when a nonfat meal preceded the test meal in an extended study, ${ }^{443}$ indicating the macronutrient meal content before or during the phase advance may impact the subsequent metabolic changes and confound the contribution of circadian disruption alone. When healthy adults were subjected to a 28-hour "day" with four scheduled isocaloric meals, they were found to have elevated postprandial glucose into the prediabetic range, decreased insulin sensitivity, elevated leptin levels, and elevated wake time BP independent of sleep efficiency, ${ }^{444}$ demonstrating the direct effect of circadian misalignment on metabolic outcomes.

\section{Children and adolescents}

Almost no studies have been carried out manipulating chronotype in a pediatric population. However, Beebe et al recently carried out a study of experimental sleep extension in adolescents and found that those with early chronotypes reduced their evening caloric intake during healthy sleep, while those with evening chronotype did not. ${ }^{445}$

\section{Pathophysiology Circadian misalignment/chronotype and MetS}

The underlying mechanisms of the adverse effects of circadian disruption on metabolic and hormonal factors remain undefined. These effects of circadian misalignment do not appear to be mediated by sleep efficiency or sleep quantity. ${ }^{425,444}$ One potential mechanism is the dysregulation of hormones such as insulin and leptin, known to be under circadian control. A study protocol of 8-hour nocturnal sleep, 28-hour extended wakefulness, and 8-hour nocturnal sleep in adults resulted in an increased glucose and insulin secretion during the biological night, ${ }^{446}$ demonstrating circadian rhythmicity of these metabolic factors. Other studies have shown leptin elevation during nocturnal sleep. ${ }^{447,448}$ Furthermore, lesions to the SCN in mice demonstrate circadian disruption in the secretion of insulin, glucose, and leptin. ${ }^{424}$ Circadian rhythmicity has also been reported in BP. ${ }^{427}$ Thus, elevations in these endocrine and metabolic factors subsequent to circadian misalignment result in hyperglycemia, IR, obesity, and hypertension, well-known risk factors for the MetS. ${ }^{449}$ Another described possible mechanism underlying the effects of circadian disruption is the internal desynchrony due to shifted feeding patterns that may uncouple peripheral oscillators present in tissues such as the liver, pancreas, and heart from the SCN. ${ }^{427}$ The relationships between such internal desynchrony and its effects on metabolism have not been studied. Lastly, molecular clock genes contribute to the function of metabolic processes, as previously described in rodent studies. In addition to the aforementioned findings in Clock mutant mice, Cry mutant mice have elevated fasting glucose levels, ${ }^{450}$ and pancreas-specific Bmall mutant mice have impaired glucose tolerance and reduced insulin sensitivity. ${ }^{451}$ Thus, mutations in core clock genes responsible for circadian rhythmicity may induce the glucose/insulin dysregulation found in MetS.

\section{Conclusion}

We have presented a comprehensive overview of the causative and associative links between sleep, sleep-disordered breathing, and MetS or its constitutive elements. The overwhelming majority of the data suggests that such sleep-metabolic interactions not only exist but also are operational in specific settings. Considering the adverse consequences associated with MetS, there is a great need for more accurate identification 
of mechanisms and personalized markers of risk. No time to sleep on these issues!

\section{Disclosure}

The authors report no conflicts of interest in this work.

\section{References}

1. Flegal KM, Carroll MD, Kit BK, Ogden CL. Prevalence of obesity and trends in the distribution of body mass index among US adults, 1999-2010. JAMA. 2012;307(5):491-497.

2. Ng M, Fleming T, Robinson M, et al. Global, regional, and national prevalence of overweight and obesity in children and adults during 1980-2013: a systematic analysis for the Global Burden of Disease Study 2013. Lancet. 2014;384(9945):766-781.

3. Ogden CL, Carroll MD, Kit BK, Flegal KM. Prevalence of childhood and adult obesity in the United States, 2011-2012. JAMA. 2014;311(8):806-814.

4. Hannon TS, Rao G, Arslanian SA. Childhood obesity and type 2 diabetes mellitus. Pediatrics. 2005;116(2):473-480.

5. Rocchini AP. Childhood obesity and a diabetes epidemic. $N$ Engl $J$ Med. 2002;346(11):854-855.

6. Morrison JA, Friedman LA, Wang P, Glueck CJ. Metabolic syndrome in childhood predicts adult metabolic syndrome and type 2 diabetes mellitus 25 to 30 years later. J Pediatr. 2008;152(2):201-206.

7. Morrison JA, Friedman LA, Gray-McGuire C. Metabolic syndrome in childhood predicts adult cardiovascular disease 25 years later: the Princeton lipid research clinics follow-up study. Pediatrics. 2007;120(2):340-345.

8. Yudkin JS. Insulin resistance and the metabolic syndrome - or the pitfalls of epidemiology. Diabetologia. 2007;50(8):1576-1586.

9. Reaven GM. Banting lecture 1988. Role of insulin resistance in human disease. Diabetes. 1988;37(12):1595-1607.

10. Aguilar M, Bhuket T, Torres S, Liu B, Wong RJ. Prevalence of the metabolic syndrome in the United States, 2003-2012. JAMA. 2015;313(19):1973-1974.

11. Cook S, Weitzman M, Auinger P, Nguyen M, Dietz WH. Prevalence of a metabolic syndrome phenotype in adolescents: findings from the third National Health and Nutrition Examination Survey, 1988-1994. Arch Pediatr Adolesc Med. 2003;157(8):821-827.

12. Johnson WD, Kroon JJ, Greenway FL, Bouchard C, Ryan D, Katzmarzyk PT. Prevalence of risk factors for metabolic syndrome in adolescents: National Health and Nutrition Examination Survey (NHANES), 2001-2006. Arch Pediatr Adolesc Med. 2009;163(4):371-377.

13. Zimmet P, Alberti G, Kaufman F, et al. The metabolic syndrome in children and adolescents. Lancet. 2007;369(9579):2059-2061.

14. Ahrens W, Moreno LA, Marild S, et al; IDEFICS Consortium. Metabolic syndrome in young children: definitions and results of the IDEFICS study. Int J Obes. 2014;38(S2):S4-S14.

15. Weiss R. Childhood metabolic syndrome: must we define it to deal with it? Diabetes Care. 2011;34(suppl 2):S171-S176.

16. Weiss R, Dziura J, Burgert TS, et al. Obesity and the metabolic syndrome in children and adolescents. N Engl J Med. 2004;350(23): 2362-2374.

17. de Ferranti SD, Gauvreau K, Ludwig DS, Neufeld EJ, Newburger JW, Rifai N. Prevalence of the metabolic syndrome in American adolescents: findings from the third national health and nutrition examination survey. Circulation. 2004;110(16):2494-2497.

18. Dhuper S, Cohen HW, Daniel J, et al. Utility of the modified ATP III defined metabolic syndrome and severe obesity as predictors of insulin resistance in overweight children and adolescents: a cross-sectional study. Cardiovasc Diabetol. 2007;6:4.

19. Epstein LH, Myers MD, Raynor HA, Saelens BE. Treatment of pediatric obesity. Pediatrics. 1998;101(3 pt 2):554-570.

20. CDC [webpage on the Internet]. Insufficient sleep is a public health problem. CDC features: data and statistics 2015. Available from: http:// www.cdc.gov/features/dssleep/. Accessed April 13, 2016.
21. Liu Y, Wheaton AG, Chapman DP, Cunningham TJ, Lu H, Croft JB. Prevalence of healthy sleep duration among adults - United States, 2014. MMWR Morb Mortal Wkly Rep. 2016;65(6):137-141.

22. National Sleep Foundation [webpage on the Internet]. 2004 Sleep in America Poll. Sleep in America 2004. Available from: https:// sleepfoundation.org/sites/default/files/FINAL\%20SOF\%202004.pdf. Accessed April 13, 2016.

23. National Sleep Foundation [webpage on the Internet]. 2006 Sleep in America Poll; 2006. Available from: http://sleepfoundation.org/sites/ default/files/2006_summary_of_findings.pdf. Accessed August 3, 2014.

24. Buxton OM, Chang A-M, Spilsbury JC, Bos T, Emsellem H, Knutson KL. Sleep in the modern family: protective family routines for child and adolescent sleep. Sleep Health. 2015;1(1):15-27.

25. Cappuccio FP, Taggart FM, Kandala NB, et al. Meta-analysis of short sleep duration and obesity in children and adults. Sleep. 2008;31(5):619-626.

26. Cespedes EM, Hu FB, Redline S, et al. Chronic insufficient sleep and diet quality: contributors to childhood obesity. Obesity (Silver Spring). 2016;24(1):184-190.

27. Taheri S. The link between short sleep duration and obesity: we should recommend more sleep to prevent obesity. Arch Dis Child. 2006;91(11):881-884.

28. Spiegel K, Tasali E, Leproult R, Van Cauter E. Effects of poor and short sleep on glucose metabolism and obesity risk. Nat Rev Endocrinol. 2009;5(5):253-261.

29. Androutsos O, Moschonis G, Mavrogianni C, et al. Identification of lifestyle patterns, including sleep deprivation, associated with insulin resistance in children: the Healthy Growth Study. Eur J Clin Nutr. 2014;68(3):344-349.

30. Spiegel K, Knutson K, Leproult R, Tasali E, Van Cauter E. Sleep loss: a novel risk factor for insulin resistance and type 2 diabetes. $J$ Appl Physiol (1985). 2005;99(5):2008-2019.

31. Bass J, Turek FW. Sleepless in America: a pathway to obesity and the metabolic syndrome? Arch Intern Med. 2005;165(1):15-16.

32. Jennings JR, Muldoon MF, Hall M, Buysse DJ, Manuck SB. Selfreported sleep quality is associated with the metabolic syndrome. Sleep. 2007;30(2):219-223.

33. Hall MH, Muldoon MF, Jennings JR, Buysse DJ, Flory JD, Manuck SB. Self-reported sleep duration is associated with the metabolic syndrome in midlife adults. Sleep. 2008;31(5):635-643.

34. Gangwisch JE, Heymsfield SB, Boden-Albala B, et al. Sleep duration as a risk factor for diabetes incidence in a large U.S. sample. Sleep. 2007;30(12):1667-1673.

35. Knutson KL, Ryden AM, Mander BA, Van Cauter E. Role of sleep duration and quality in the risk and severity of type 2 diabetes mellitus. Arch Intern Med. 2006;166(16):1768-1774.

36. Shan Z, Ma H, Xie M, et al. Sleep duration and risk of type 2 diabetes: a meta-analysis of prospective studies. Diabetes Care. 2015;38(3):529-537.

37. Eguchi K, Pickering TG, Schwartz JE, et al. Short sleep duration as an independent predictor of cardiovascular events in Japanese patients with hypertension. Arch Intern Med. 2008;168(20):2225-2231.

38. Hoevenaar-Blom MP, Spijkerman AM, Kromhout D, van den Berg JF, Verschuren WM. Sleep duration and sleep quality in relation to 12-year cardiovascular disease incidence: the MORGEN study. Sleep. 2011;34(11):1487-1492.

39. Cappuccio FP, Cooper D, D'Elia L, Strazzullo P, Miller MA. Sleep duration predicts cardiovascular outcomes: a systematic review and metaanalysis of prospective studies. Eur Heart J. 2011;32(12):1484-1492.

40. Hammond EC. Some preliminary findings on physical complaints from a prospective study of 1,064,004 men and women. Am J Public Health Nations Health. 1964;54:11-23.

41. Wingard DL, Berkman LF. Mortality risk associated with sleeping patterns among adults. Sleep. 1983;6(2):102-107.

42. Cappuccio FP, D’Elia L, Strazzullo P, Miller MA. Sleep duration and all-cause mortality: a systematic review and meta-analysis of prospective studies. Sleep. 2010;33(5):585-592. 
43. Liu TZ, Xu C, Rota M, et al. Sleep duration and risk of all-cause mortality: a flexible, non-linear, meta-regression of 40 prospective cohort studies. Sleep Med Rev. Epub 2016 Mar 3.

44. Patel SR, Blackwell T, Redline S, et al; Osteoporotic Fractures in Men Research Group; Study of Osteoporotic Fractures Research Group. The association between sleep duration and obesity in older adults. Int J Obes (Lond). 2008;32(12):1825-1834.

45. Buxton OM, Marcelli E. Short and long sleep are positively associated with obesity, diabetes, hypertension, and cardiovascular disease among adults in the United States. Soc Sci Med. 2010;71(5):1027-1036.

46. Chaput JP, Bouchard C, Tremblay A. Change in sleep duration and visceral fat accumulation over 6 years in adults. Obesity (Silver Spring). 2014;22(5):E9-E12.

47. Vgontzas AN, Fernandez-Mendoza J, Miksiewicz T, et al. Unveiling the longitudinal association between short sleep duration and the incidence of obesity: the Penn State Cohort. Int J Obes (Lond). 2014;38(6):825-832.

48. Taheri S, Lin L, Austin D, Young T, Mignot E. Short sleep duration is associated with reduced leptin, elevated ghrelin, and increased body mass index. PLoS Med. 2004;1(3):e62.

49. Ford ES, Li C, Wheaton AG, Chapman DP, Perry GS, Croft JB. Sleep duration and body mass index and waist circumference among U.S. adults. Obesity (Silver Spring). 2014;22(2):598-607.

50. Grodstein F, Stampfer M. The epidemiology of coronary heart disease and estrogen replacement in postmenopausal women. Prog Cardiovasc Dis. 1995;38(3):199-210.

51. Anujuo K, Stronks K, Snijder MB, et al. Relationship between short sleep duration and cardiovascular risk factors in a multi-ethnic cohort - the helius study. Sleep Med. 2015;16(12):1482-1488.

52. Donat M, Brown C, Williams N, et al. Linking sleep duration and obesity among black and white US adults. Clin Pract (Lond). 2013;10(5):661-667.

53. Gottlieb DJ, Redline S, Nieto FJ, et al. Association of usual sleep duration with hypertension: the Sleep Heart Health Study. Sleep. 2006;29(8):1009-1014.

54. Gangwisch JE, Heymsfield SB, Boden-Albala B, et al. Short sleep duration as a risk factor for hypertension: analyses of the first national health and nutrition examination survey. Hypertension. 2006;47(5):833-839.

55. Kim J, Jo I. Age-dependent association between sleep duration and hypertension in the adult Korean population. Am J Hypertens. 2010;23(12):1286-1291.

56. van den Berg JF, Tulen JH, Neven AK, et al. Sleep duration and hypertension are not associated in the elderly. Hypertension. 2007;50(3):585-589.

57. Lopez-Garcia E, Faubel R, Guallar-Castillon P, Leon-Munoz L, Banegas JR, Rodriguez-Artalejo F. Self-reported sleep duration and hypertension in older Spanish adults. J Am Geriatr Soc. 2009;57(4): 663-668.

58. Wang Q, Xi B, Liu M, Zhang Y, Fu M. Short sleep duration is associated with hypertension risk among adults: a systematic review and meta-analysis. Hypertens Res. 2012;35(10):1012-1018.

59. Stranges S, Dorn JM, Cappuccio FP, et al. A population-based study of reduced sleep duration and hypertension: the strongest association may be in premenopausal women. J Hypertens. 2010;28(5): 896-902.

60. Cappuccio FP, Stranges S, Kandala N-B, et al. Gender-specific associations of short sleep duration with prevalent and incident hypertension: the Whitehall II Study. Hypertension. 2007;50(4):693-700.

61. Fang J, Wheaton AG, Keenan NL, Greenlund KJ, Perry GS, Croft JB. Association of sleep duration and hypertension among US adults varies by age and sex. Am J Hypertens. 2012;25(3):335-341.

62. Yaggi HK, Araujo AB, McKinlay JB. Sleep duration as a risk factor for the development of type 2 diabetes. Diabetes Care. 2006;29(3): 657-661.

63. Ayas NT, White DP, Al-Delaimy WK, et al. A prospective study of self-reported sleep duration and incident diabetes in women. Diabetes Care. 2003;26(2):380-384.

64. Chaput JP, Despres JP, Bouchard C, Tremblay A. Association of sleep duration with type 2 diabetes and impaired glucose tolerance. Diabetologia. 2007;50(11):2298-2304.
65. Pyykkonen AJ, Isomaa B, Pesonen AK, et al. Sleep duration and insulin resistance in individuals without type 2 diabetes: the PPP-Botnia study. Ann Med. 2014;46(5):324-329.

66. Chang JK, Koo M, Kao VY, Chiang JK. Association of sleep duration and insulin resistance in Taiwanese vegetarians. BMC Public Health. 2012;12:666

67. Beihl DA, Liese AD, Haffner SM. Sleep duration as a risk factor for incident type 2 diabetes in a multiethnic cohort. Ann Epidemiol. 2009;19(5):351-357.

68. Jackson CL, Redline S, Kawachi I, Hu FB. Association between sleep duration and diabetes in black and white adults. Diabetes Care. 2013;36(11):3557-3565.

69. Choi KM, Lee JS, Park HS, Baik SH, Choi DS, Kim SM. Relationship between sleep duration and the metabolic syndrome: Korean National Health and Nutrition Survey 2001. Int J Obes (Lond). 2008;32(7):1091-1097.

70. Najafian J, Toghianifar N, Mohammadifard N, Nouri F. Association between sleep duration and metabolic syndrome in a population-based study: Isfahan Healthy Heart Program. JRes Med Sci. 2011;16(6):801-806.

71. Iftikhar IH, Donley MA, Mindel J, Pleister A, Soriano S, Magalang UJ. Sleep duration and metabolic syndrome. An updated dose-risk metaanalysis. Ann Am Thorac Soc. 2015;12(9):1364-1372.

72. Ju SY, Choi WS. Sleep duration and metabolic syndrome in adult populations: a meta-analysis of observational studies. Nutr Diabetes. 2013;3:e65.

73. Wu J, Xu G, Shen L, et al. Daily sleep duration and risk of metabolic syndrome among middle-aged and older Chinese adults: cross-sectional evidence from the Dongfeng-Tongji cohort study. BMC Public Health. 2015;15:178.

74. Xi B, He D, Zhang M, Xue J, Zhou D. Short sleep duration predicts risk of metabolic syndrome: a systematic review and meta-analysis. Sleep Med Rev. 2014;18(4):293-297.

75. Wu MC, Yang YC, Wu JS, Wang RH, Lu FH, Chang CJ. Short sleep duration associated with a higher prevalence of metabolic syndrome in an apparently healthy population. Prev Med. 2012;55(4):305-309.

76. Arora T, Jiang CQ, Thomas GN, et al. Self-reported long total sleep duration is associated with metabolic syndrome: the Guangzhou Biobank Cohort Study. Diabetes Care. 2011;34(10):2317-2319.

77. Kim JY, Yadav D, Ahn SV, et al. A prospective study of total sleep duration and incident metabolic syndrome: the ARIRANG study. Sleep Med. 2015;16(12):1511-1515.

78. Chandola T, Ferrie JE, Perski A, Akbaraly T, Marmot MG. The effect of short sleep duration on coronary heart disease risk is greatest among those with sleep disturbance: a prospective study from the Whitehall II cohort. Sleep. 2010;33(6):739-744.

79. Ayas NT, White DP, Manson JE, et al. A prospective study of sleep duration and coronary heart disease in women. Arch Intern Med. 2003;163(2):205-209.

80. Sabanayagam C, Shankar A. Sleep duration and cardiovascular disease: results from the national health interview survey. Sleep. 2010;33(8):1037-1042.

81. Ford ES. Habitual sleep duration and predicted 10-year cardiovascular risk using the pooled cohort risk equations among US adults. $J \mathrm{Am}$ Heart Assoc. 2014;3(6):e001454.

82. Hoevenaar-Blom MP, Spijkerman AM, Kromhout D, Verschuren WM. Sufficient sleep duration contributes to lower cardiovascular disease risk in addition to four traditional lifestyle factors: the MORGEN study. Eur J Prev Cardiol. 2014;21(11):1367-1375.

83. Meisinger C, Heier M, Lowel H, Schneider A, Doring A. Sleep duration and sleep complaints and risk of myocardial infarction in middle-aged men and women from the general population: the MONICA/KORA Augsburg cohort study. Sleep. 2007;30(9):1121-1127.

84. Strand LB, Tsai MK, Gunnell D, Janszky I, Wen CP, Chang SS Self-reported sleep duration and coronary heart disease mortality: a large cohort study of 400,000 Taiwanese adults. Int J Cardiol. 2016;207:246-251.

85. Hirshkowitz M, Whiton K, Albert SM, et al. National sleep foundation's sleep time duration recommendations: methodology and results summary. Sleep Health. 2015;1(1):40-43. 
86. 2014 Sleep in America Poll. Sleep in the modern family. Sleep Health. 2014;1(2):e13.

87. 2006 Sleep in America Poll. Teens and sleep. Sleep Health. 2006;1(2):e5.

88. Eaton DK, Kann L, Kinchen S, et al. Youth risk behavior surveillance - United States, 2009. MMWR Morb Mortal Wkly Rep. 2010; 59(5):1-142.

89. Matthews KA, Hall M, Dahl RE. Sleep in healthy black and white adolescents. Pediatrics. 2014;133(5):e1189-e1196.

90. Rudnicka AR, Nightingale CM, Donin AS, et al. Sleep duration and risk markers for type 2 diabetes: a cross-sectional study in children aged 9-10 years. Lancet. 2015;386:S4.

91. He F, Bixler EO, Fernandez-Mendoza J, et al. Abstract P312: lack of association between habitual sleep duration and obesity measures in adolescents with adequate sleep. Circulation. 2016;133(suppl 1):A312.

92. Taveras EM, Rifas-Shiman SL, Oken E, Gunderson EP, Gillman MW. Short sleep duration in infancy and risk of childhood overweight. Arch Pediatr Adolesc Med. 2008;162(4):305-311.

93. von Kries R, Toschke AM, Wurmser H, Sauerwald T, Koletzko B. Reduced risk for overweight and obesity in 5- and 6-y-old children by duration of sleep - a cross-sectional study. Int J Obes Relat Metab Disord. 2002;26(5):710-716.

94. Touchette E, Petit D, Tremblay RE, et al. Associations between sleep duration patterns and overweight/obesity at age 6. Sleep. 2008;31(11):1507-1514.

95. Taveras EM, Gillman MW, Pena MM, Redline S, Rifas-Shiman SL. Chronic sleep curtailment and adiposity. Pediatrics. 2014;133(6):1013-1022.

96. Chaput JP, Brunet M, Tremblay A. Relationship between short sleeping hours and childhood overweight/obesity: results from the 'Quebec en Forme' Project. Int J Obes. 2006;30(7):1080-1085.

97. Sluggett L, Wagner SL, Hardy C, Harris RL. Associations between sleep duration and indicators of cardiometabolic disease in Canadian children and adolescents: analyses of the 2007-2009 Canadian health measures survey. Child Obes. Epub 2016 May 19.

98. Kong AP, Wing YK, Choi KC, et al. Associations of sleep duration with obesity and serum lipid profile in children and adolescents. Sleep Med. 2011;12(7):659-665.

99. Garaulet M, Ortega FB, Ruiz JR, et al. Short sleep duration is associated with increased obesity markers in European adolescents: effect of physical activity and dietary habits. The HELENA study. Int J Obes (Lond). 2011;35(10):1308-1317.

100. Mitchell JA, Rodriguez D, Schmitz KH, Audrain-McGovern J. Sleep duration and adolescent obesity. Pediatrics. 2013;131(5):e1428-e1434.

101. Spruyt K, Molfese DL, Gozal D. Sleep duration, sleep regularity, body weight, and metabolic homeostasis in school-aged children. Pediatrics. 2011;127(2):e345-e352.

102. He F, Bixler EO, Berg A, et al. Habitual sleep variability, not sleep duration, is associated with caloric intake in adolescents. Sleep Med. 2015;16(7):856-861.

103. Landhuis CE, Poulton R, Welch D, Hancox RJ. Childhood sleep time and long-term risk for obesity: a 32-year prospective birth cohort study. Pediatrics. 2008;122(5):955-960.

104. Eisenmann JC, Ekkekakis P, Holmes M. Sleep duration and overweight among Australian children and adolescents. Acta Paediatr. 2006;95(8):956-963.

105. Hitze B, Bosy-Westphal A, Bielfeldt F, et al. Determinants and impact of sleep duration in children and adolescents: data of the Kiel Obesity Prevention Study. Eur J Clin Nutr. 2009;63(6):739-746.

106. Pedrosa R, Sena A, Cardoso A, et al. Sleep duration and cardiovascular risk in children and adolescents with overweight/obesity. Eur Respir J. 2013;42(suppl):57.

107. Valrie CR, Bond K, Lutes LD, Carraway M, Collier DN. Relationship of sleep quality, baseline weight status, and weight-loss responsiveness in obese adolescents in an immersion treatment program. Sleep Med. 2015;16(3):432-434.

108. Navarro-Solera M, Carrasco-Luna J, Pin-Arboledas G, GonzalezCarrascosa R, Soriano JM, Codoner-Franch P. Short sleep duration is related to emerging cardiovascular risk factors in obese children. $J$ Pediatr Gastroenterol Nutr. 2015;61(5):571-576.
109. Schäfer AA, Domingues MR, Dahly DL, et al. Sleep duration trajectories and body composition in adolescents: prospective birth cohort study. PLoS One. 2016;11(3):e0152348.

110. Sampei M, Dakeishi M, Wood DC, Murata K. Impact of total sleep duration on blood pressure in preschool children. Biomed Res. 2006;27(3):111-115.

111. Au CT, Ho CKW, Wing YK, Lam HS, Li AM. Acute and chronic effects of sleep duration on blood pressure. Pediatrics. 2014;133(1):e64-e72.

112. Javaheri S, Storfer-Isser A, Rosen CL, Redline S. Sleep quality and elevated blood pressure in adolescents. Circulation. 2008;118(10):1034-1040.

113. Hannon TS, Tu W, Watson SE, Jalou H, Chakravorty S, Arslanian SA. Morning blood pressure is associated with sleep quality in obese adolescents. J Pediatr. 2014;164(2):313-317.

114. Mezick EJ, Hall M, Matthews KA. Sleep duration and ambulatory blood pressure in black and white adolescents. Hypertension. 2012;59(3):747-752.

115. Rodriguez-Colon SM, He F, Bixler EO, et al. Sleep variability and cardiac autonomic modulation in adolescents - Penn State Child Cohort (PSCC) study. Sleep Med. 2015;16(1):67-72.

116. Bayer O, Neuhauser H, von Kries R. Sleep duration and blood pressure in children: a cross-sectional study. J Hypertens. 2009;27(9):1789-1793.

117. Martikainen S, Pesonen AK, Feldt K, et al. Poor sleep and cardiovascular function in children. Hypertension. 2011;58(1):16-21.

118. Flint J, Kothare SV, Zihlif M, et al. Association between inadequate sleep and insulin resistance in obese children. J Pediatr. 2007;150(4):364-369.

119. Sayin FK, Buyukinan M. Sleep duration and media time have a major impact on insulin resistance and metabolic risk factors in obese children and adolescents. Child Obes. Epub 2016 Mar 15.

120. Matthews KA, Dahl RE, Owens JF, Lee L, Hall M. Sleep duration and insulin resistance in healthy black and white adolescents. Sleep. 2012;35(10):1353-1358.

121. Dorenbos E, Rijks JM, Adam TC, Westerterp-Plantenga MS, Vreugdenhil AC. Sleep efficiency as a determinant of insulin sensitivity in overweight and obese adolescents. Diabetes Obes Metab. 2015;17(suppl 1): 90-98.

122. De Bernardi Rodrigues AM, da Silva Cde C, Vasques AC, et al; Brazilian Metabolic Syndrome Study (BRAMS) Investigators. Association of sleep deprivation with reduction in insulin sensitivity as assessed by the hyperglycemic clamp technique in adolescents. JAMA Pediatr. 2016;170(5):487-494.

123. Tian Z, Ye T, Zhang X, et al. Sleep duration and hyperglycemia among obese and nonobese children aged 3 to 6 years. Arch Pediatr Adolesc Med. 2010;164(1):46-52.

124. Zhu Y, Li AM, Au CT, et al. Association between sleep architecture and glucose tolerance in children and adolescents. $J$ Diabetes. 2015;7(1):10-15.

125. Koren D, LevittKatzLE, BrarPC, Gallagher PR, Berkowitz RI, Brooks LJ. Sleep architecture and glucose and insulin homeostasis in obese adolescents. Diabetes Care. 2011;34(11):2442-2447.

126. Koren D, Gozal D, Philby MF, Bhattacharjee R, Kheirandish-Gozal L. Impact of obstructive sleep apnoea on insulin resistance in nonobese and obese children. Eur Respir J. 2016;47(4):1152-1161.

127. Dabelea D, Mayer-Davis EJ, Saydah S, et al; SEARCH for Diabetes in Youth Study. Prevalence of type 1 and type 2 diabetes among children and adolescents from 2001 to 2009. JAMA. 2014;311(17):1778-1786.

128. Gangwisch JE, Malaspina D, Babiss LA, et al. Short sleep duration as a risk factor for hypercholesterolemia: analyses of the National Longitudinal Study of Adolescent Health. Sleep. 2010;33(7):956-961.

129. Lee JA, Park HS. Relation between sleep duration, overweight, and metabolic syndrome in Korean adolescents. Nutr Metab Cardiovasc Dis. 2014;24(1):65-71.

130. Azadbakht L, Kelishadi R, Khodarahmi M, et al. The association of sleep duration and cardiometabolic risk factors in a national sample of children and adolescents: the CASPIAN III study. Nutrition. 2013;29(9):1133-1141.

131. Berentzen NE, Smit HA, Bekkers MBM, et al. Time in bed, sleep quality and associations with cardiometabolic markers in children: the prevention and incidence of asthma and mite allergy birth cohort study. J Sleep Res. 2014;23(1):3-12. 
132. Narang I, Manlhiot C, Davies-Shaw J, et al. Sleep disturbance and cardiovascular risk in adolescents. CMAJ. 2012;184(17):E913-E920.

133. Rey-Lopez JP, de Carvalho HB, de Moraes AC, et al; HELENA study. Sleep time and cardiovascular risk factors in adolescents: the HELENA (Healthy Lifestyle in Europe by Nutrition in Adolescence) study. Sleep Med. 2014;15(1):104-110.

134. Hjorth MF, Chaput JP, Damsgaard CT, et al. Low physical activity level and short sleep duration are associated with an increased cardiometabolic risk profile: a longitudinal study in 8-11 year old Danish children. PLoS One. 2014;9(8):e104677.

135. Fadzlina A, Harun F, Nurul Haniza M, et al. Metabolic syndrome among 13 year old adolescents: prevalence and risk factors. BMC Public Health. 2014;14(3):1-8.

136. Sung V, Beebee DW, Vandyke R, et al. Does sleep duration predict metabolic risk in obese adolescents attending tertiary services? A cross-sectional study. Sleep. 2011;34(7):891-898.

137. Spaeth AM, Dinges DF, Goel N. Effects of experimental sleep restriction on weight gain, caloric intake, and meal timing in healthy adults Sleep. 2013;36(7):981-990.

138. Jung CM, Melanson EL, Frydendall EJ, Perreault L, Eckel RH, Wright KP. Energy expenditure during sleep, sleep deprivation and sleep following sleep deprivation in adult humans. J Physiol. 2011;589(pt 1):235-244.

139. Markwald RR, Melanson EL, Smith MR, et al. Impact of insufficient sleep on total daily energy expenditure, food intake, and weight gain Proc Natl Acad Sci USA. 2013;110(14):5695-5700.

140. St-Onge MP, Roberts AL, Chen J, et al. Short sleep duration increases energy intakes but does not change energy expenditure in normalweight individuals. Am J Clin Nutr. 2011;94(2):410-416.

141. Nedeltcheva AV, Kilkus JM, Imperial J, Kasza K, Schoeller DA, Penev PD. Sleep curtailment is accompanied by increased intake of calories from snacks. Am J Clin Nutr. 2009;89(1):126-133.

142. Spaeth AM, Dinges DF, Goel N. Sex and race differences in caloric intake during sleep restriction in healthy adults. Am J Clin Nutr. 2014;100(2):559-566.

143. Brondel L, Romer MA, Nougues PM, Touyarou P, Davenne D. Acute partial sleep deprivation increases food intake in healthy men. $A m J$ Clin Nutr. 2010;91(6):1550-1559.

144. Calvin AD, Carter RE, Adachi T, et al. Effects of experimental sleep restriction on caloric intake and activity energy expenditure. Chest. 2013;144(1):79-86.

145. Bromley LE, Booth JN 3rd, Kilkus JM, Imperial JG, Penev PD. Sleep restriction decreases the physical activity of adults at risk for type 2 diabetes. Sleep. 2012;35(7):977-984.

146. Tasali E, Chapotot F, Wroblewski K, Schoeller D. The effects of extended bedtimes on sleep duration and food desire in overweight young adults: a home-based intervention. Appetite. 2014;80:220-224.

147. Schmid SM, Hallschmid M, Jauch-Chara K, Born J, Schultes B. A single night of sleep deprivation increases ghrelin levels and feelings of hunger in normal-weight healthy men. J Sleep Res. 2008;17(3):331-334.

148. Spiegel K, Tasali E, Penev P, Van Cauter E. Brief communication: sleep curtailment in healthy young men is associated with decreased leptin levels, elevated ghrelin levels, and increased hunger and appetite. Ann Intern Med. 2004;141(11):846-850.

149. Omisade A, Buxton OM, Rusak B. Impact of acute sleep restriction on cortisol and leptin levels in young women. Physiol Behav. 2010;99(5):651-656.

150. St-Onge MP, O'Keeffe M, Roberts AL, RoyChoudhury A, Laferrere B. Short sleep duration, glucose dysregulation and hormonal regulation of appetite in men and women. Sleep. 2012;35(11):1503-1510.

151. Broussard JL, Kilkus JM, Delebecque F, et al. Elevated ghrelin predicts food intake during experimental sleep restriction. Obesity (Silver Spring). 2016;24(1):132-138.

152. Spiegel K, Leproult R, L'Hermite-Baleriaux M, Copinschi G, Penev PD, Van Cauter E. Leptin levels are dependent on sleep duration: relationships with sympathovagal balance, carbohydrate regulation, cortisol, and thyrotropin. J Clin Endocrinol Metab. 2004;89(11): 5762-5771.

153. Spiegel K, Leproult R, Van Cauter E. Impact of sleep debt on metabolic and endocrine function. Lancet. 1999;354(9188):1435-1439.
154. Magee CA, Huang X-F, Iverson DC, Caputi P. Acute sleep restriction alters neuroendocrine hormones and appetite in healthy male adults. Sleep Biol Rhythms. 2009;7(2):125-127.

155. Killick R, Hoyos CM, Melehan KL, Dungan GC 2nd, Poh J, Liu PY. Metabolic and hormonal effects of 'catch-up' sleep in men with chronic, repetitive, lifestyle-driven sleep restriction. Clin Endocrinol (Oxf). 2015;83(4):498-507.

156. Buxton OM, Pavlova M, Reid EW, Wang W, Simonson DC, Adler GK. Sleep restriction for 1 week reduces insulin sensitivity in healthy men. Diabetes. 2010;59(9):2126-2133.

157. Nedeltcheva AV, Kessler L, Imperial J, Penev PD. Exposure to recurrent sleep restriction in the setting of high caloric intake and physical inactivity results in increased insulin resistance and reduced glucose tolerance. J Clin Endocrinol Metab. 2009;94(9):3242-3250.

158. Donga E, van Dijk M, van Dijk JG, et al. A single night of partial sleep deprivation induces insulin resistance in multiple metabolic pathways in healthy subjects. J Clin Endocrinol Metab. 2010;95(6):2963-2968.

159. Faraut B, Nakib S, Drogou C, et al. Napping reverses the salivary interleukin-6 and urinary norepinephrine changes induced by sleep restriction. J Clin Endocrinol Metab. 2015;100(3):E416-E426.

160. van Leeuwen WM, Lehto M, Karisola P, et al. Sleep restriction increases the risk of developing cardiovascular diseases by augmenting proinflammatory responses through IL-17 and CRP. PLoS One. 2009;4(2):e4589.

161. Ferrie JE, Kivimaki M, Akbaraly TN, et al. Associations between change in sleep duration and inflammation: findings on C-reactive protein and interleukin 6 in the Whitehall II Study. Am J Epidemiol. 2013;178(6):956-961.

162. Broussard JL, Ehrmann DA, Van Cauter E, Tasali E, Brady MJ. Impaired insulin signaling in human adipocytes after experimental sleep restriction: a randomized, crossover study. Ann Intern Med. 2012;157(8):549-557.

163. Cedernaes J, Osler ME, Voisin S, et al. Acute sleep loss induces tissuespecific epigenetic and transcriptional alterations to circadian clock genes in men. J Clin Endocrinol Metab. 2015;100(9):E1255-E1261.

164. Moller-Levet CS, Archer SN, Bucca G, et al. Effects of insufficient sleep on circadian rhythmicity and expression amplitude of the human blood transcriptome. Proc Natl Acad Sci U SA. 2013;110(12): E1132-E1141.

165. Leproult R, Deliens G, Gilson M, Peigneux P. Beneficial impact of sleep extension on fasting insulin sensitivity in adults with habitual sleep restriction. Sleep. 2015;38(5):707-715.

166. Arnal PJ, Drogou C, Sauvet F, et al. Effect of sleep extension on the subsequent testosterone, cortisol and prolactin responses to total sleep deprivation and recovery. $J$ Neuroendocrinol. 2016;28(2):12346.

167. Ogawa Y, Kanbayashi T, Saito Y, et al. Total sleep deprivation elevates blood pressure through arterial baroreflex resetting: a study with microneurographic technique. Sleep. 2003;26(8):986-989.

168. Zhong X, Hilton HJ, Gates GJ, et al. Increased sympathetic and decreased parasympathetic cardiovascular modulation in normal humans with acute sleep deprivation. J Appl Physiol (1985) 2005;98(6):2024-2032.

169. Lusardi P, Zoppi A, Preti P, Pesce RM, Piazza E, Fogari R. Effects of insufficient sleep on blood pressure in hypertensive patients: a 24-h study. Am J Hypertens. 1999;12(1 pt 1):63-68.

170. Covassin N, Bukartyk J, Sahakyan K, et al. Experimental sleep restriction increases nocturnal blood pressure and attenuates blood pressure dipping in healthy individuals. JAm Coll Cardiol. 2015;65(10_S):61352-61353.

171. Sauvet F, Leftheriotis G, Gomez-Merino D, et al. Effect of acute sleep deprivation on vascular function in healthy subjects. $J$ Appl Physiol (1985). 2010;108(1):68-75.

172. Calvin AD, Covassin N, Kremers WK, et al. Experimental sleep restriction causes endothelial dysfunction in healthy humans. $J \mathrm{Am}$ Heart Assoc. 2014;3(6):e001143.

173. Yang H, Durocher JJ, Larson RA, Dellavalla JP, Carter JR. Total sleep deprivation alters cardiovascular reactivity to acute stressors in humans. J Appl Physiol (1985). 2012;113(6):903-908.

174. Holmes AL, Burgess HJ, Dawson D. Effects of sleep pressure on endogenous cardiac autonomic activity and body temperature. $J$ Appl Physiol (1985). 2002;92(6):2578-2584. 
175. Sunbul M, Kanar BG, Durmus E, Kivrak T, Sari I. Acute sleep deprivation is associated with increased arterial stiffness in healthy young adults. Sleep Breath. 2014;18(1):215-220.

176. Cakici M, Dogan A, Cetin M, et al. Negative effects of acute sleep deprivation on left ventricular functions and cardiac repolarization in healthy young adults. Pacing Clin Electrophysiol. 2015;38(6):713-722.

177. O'Keeffe M, Roberts AL, Kelleman M, Roychoudhury A, St-Onge MP. No effects of short-term sleep restriction, in a controlled feeding setting, on lipid profiles in normal-weight adults. J Sleep Res. 2013;22(6):717-720.

178. Reynolds AC, Dorrian J, Liu PY, et al. Impact of five nights of sleep restriction on glucose metabolism, leptin and testosterone in young adult men. PLoS One. 2012;7(7):e41218.

179. Kerkhofs M, Boudjeltia KZ, Stenuit P, Brohee D, Cauchie P, Vanhaeverbeek M. Sleep restriction increases blood neutrophils, total cholesterol and low density lipoprotein cholesterol in postmenopausal women: a preliminary study. Maturitas. 2007;56(2):212-215.

180. Boudjeltia KZ, Faraut B, Esposito MJ, et al. Temporal dissociation between myeloperoxidase (MPO)-modified LDL and MPO elevations during chronic sleep restriction and recovery in healthy young men. PLoS One. 2011;6(11):e28230.

181. Delporte C, Van Antwerpen P, Vanhamme L, Roumeguere T, Zouaoui Boudjeltia K. Low-density lipoprotein modified by myeloperoxidase in inflammatory pathways and clinical studies. Mediators Inflamm. 2013;2013:971579.

182. Aho V, Ollila HM, Kronholm E, et al. Prolonged sleep restriction induces changes in pathways involved in cholesterol metabolism and inflammatory responses. Sci Rep. 2016;6:24828.

183. Poirier A, Gendron M, Vriend J, Davidson F, Corkum P. The impact of sleep restriction on daytime movement in typically developing children. Atten Defic Hyperact Disord. 2016;8(1):53-58.

184. Hart CN, Carskadon MA, Considine RV, et al. Changes in children's sleep duration on food intake, weight, and leptin. Pediatrics. 2013;132(6):e1473-e1480.

185. Weiss A, Xu F, Storfer-Isser A, Thomas A, Ievers-Landis CE, Redline S. The association of sleep duration with adolescents' fat and carbohydrate consumption. Sleep. 2010;33(9):1201-1209.

186. Beebe DW, Simon S, Summer S, Hemmer S, Strotman D, Dolan LM. Dietary intake following experimentally restricted sleep in adolescents. Sleep. 2013;36(6):827-834.

187. Simon SL, Field J, Miller LE, DiFrancesco M, Beebe DW. Sweet/ dessert foods are more appealing to adolescents after sleep restriction. PLoS One. 2015;10(2):e0115434.

188. O’Sullivan KL, Dumin M, Kheirandish-Gozal L, Bhattacharjee R, Gozal D, Koren D. The effects of acute sleep restriction on weight and cardiometabolic risk indices in obese adolescents. In: Cardiometabolic Risk/Vascular Biology (posters): FRI-676; 2016; Boston.

189. Klingenberg L, Chaput JP, Holmback U, et al. Acute sleep restriction reduces insulin sensitivity in adolescent boys. Sleep. 2013;36(7):1085-1090.

190. Young T, Skatrud J, Peppard PE. Risk factors for obstructive sleep apnea in adults. JAMA. 2004;291(16):2013-2016.

191. Verhulst SL, Schrauwen N, Haentjens D, et al. Sleep-disordered breathing in overweight and obese children and adolescents: prevalence, characteristics and the role of fat distribution. Arch Dis Child. 2007;92(3):205-208.

192. Yuan H, Schwab RJ, Kim C, et al. Relationship between body fat distribution and upper airway dynamic function during sleep in adolescents. Sleep. 2013;36(8):1199-1207.

193. Arens R, Muzumdar H. Childhood obesity and obstructive sleep apnea syndrome. J Appl Physiol (1985). 2010;108(2):436-444.

194. Ip MS, Lam B, Ng MM, Lam WK, Tsang KW, Lam KS. Obstructive sleep apnea is independently associated with insulin resistance. Am J Respir Crit Care Med. 2002;165(5):670-676.

195. Pamidi S, Wroblewski K, Broussard J, et al. Obstructive sleep apnea in young lean men: impact on insulin sensitivity and secretion. Diabetes Care. 2012;35(11):2384-2389.
196. Punjabi NM, Shahar E, Redline S, et al; Sleep Heart Health Study. Sleep-disordered breathing, glucose intolerance, and insulin resistance: the sleep heart health study. Am J Epidemiol. 2004;160(6):521-530.

197. Parish JM, Adam T, Facchiano L. Relationship of metabolic syndrome and obstructive sleep apnea. J Clin Sleep Med. 2007;3(5):467-472.

198. Muraki I, Tanigawa T, Yamagishi K, et al; CIRCS Investigators. Nocturnal intermittent hypoxia and the development of type 2 diabetes: the circulatory risk in communities study (CIRCS). Diabetologia. 2010;53(3):481-488.

199. Tasali E, Mokhlesi B, Van Cauter E. Obstructive sleep apnea and type 2 diabetes: interacting epidemics. Chest. 2008;133(2):496-506.

200. Babu AR, Herdegen J, Fogelfeld L, Shott S, Mazzone T. Type 2 diabetes, glycemic control, and continuous positive airway pressure in obstructive sleep apnea. Arch Intern Med. 2005;165(4):447-452.

201. Grimaldi D, Beccuti G, Touma C, Van Cauter E, Mokhlesi B. Association of obstructive sleep apnea in rapid eye movement sleep with reduced glycemic control in type 2 diabetes: therapeutic implications. Diabetes Care. 2014;37(2):355-363.

202. Aronsohn RS, Whitmore H, Van Cauter E, Tasali E. Impact of untreated obstructive sleep apnea on glucose control in type 2 diabetes. Am J Respir Crit Care Med. 2010;181(5):507-513.

203. Newman AB, Nieto FJ, Guidry U, et al; Sleep Heart Health Study Research Group. Relation of sleep-disordered breathing to cardiovascular disease risk factors: the sleep heart health study. Am J Epidemiol. 2001;154(1):50-59.

204. Yaggi HK, Concato J, Kernan WN, Lichtman JH, Brass LM, Mohsenin V. Obstructive sleep apnea as a risk factor for stroke and death. $N E n g l$ J Med. 2005;353(19):2034-2041.

205. Partinen M, Jamieson A, Guilleminault C. Long-term outcome for obstructive sleep apnea syndrome patients. Mortality. Chest. 1988;94(6):1200-1204.

206. Marshall NS, Wong KK, Liu PY, Cullen SR, Knuiman MW, Grunstein RR. Sleep apnea as an independent risk factor for all-cause mortality: the Busselton Health Study. Sleep. 2008;31(8):1079-1085.

207. Epstein LJ, Kristo D, Strollo PJ Jr, et al; Adult Obstructive Sleep Apnea Task Force of the American Academy of Sleep Medicine. Clinical guideline for the evaluation, management and long-term care of obstructive sleep apnea in adults. J Clin Sleep Med. 2009;5(3):263-276.

208. Marcus CL, Brooks LJ, Draper KA, et al; American Academy of Pediatrics. Diagnosis and management of childhood obstructive sleep apnea syndrome. Pediatrics. 2012;130(3):576-584.

209. Marcus CL. Sleep-disordered breathing in children. Am J Respir Crit Care Med. 2001;164(1):16-30.

210. Fuentes-Pradera MA, Sánchez-Armengol Á, Capote-Gil F, et al. Effects of sex on sleep-disordered breathing in adolescents. Eur Respir J. 2004;23(2):250-254.

211. Dancey DR, Hanly PJ, Soong C, Lee B, Hoffstein V. Impact of menopause on the prevalence and severity of sleep apnea. Chest. 2001;120(1):151-155

212. Ronen O, Malhotra A, Pillar G. Influence of gender and age on upper-airway length during development. Pediatrics. 2007;120(4):e1028-e1034.

213. Cistulli PA, Grunstein RR, Sullivan CE. Effect of testosterone administration on upper airway collapsibility during sleep. Am J Respir Crit Care Med. 1994;149(2 pt 1):530-532.

214. Peppard PE, Young T, Barnet JH, Palta M, Hagen EW, Hla KM. Increased prevalence of sleep-disordered breathing in adults. $\mathrm{Am} \mathrm{J}$ Epidemiol. 2013;177(9):1006-1014.

215. Romero-Corral A, Caples SM, Lopez-Jimenez F, Somers VK. Interactions between obesity and obstructive sleep apnea: implications for treatment. Chest. 2010;137(3):711-719.

216. Resta O, Foschino-Barbaro MP, Legari G, et al. Sleep-related breathing disorders, loud snoring and excessive daytime sleepiness in obese subjects. Int J Obes Relat Metab Disord. 2001;25(5):669-675.

217. Schwartz AR, Patil SP, Laffan AM, Polotsky V, Schneider H, Smith PL. Obesity and obstructive sleep apnea. Proc Am Thorac Soc. 2008;5(2):185-192. 
218. Fritscher LG, Mottin CC, Canani S, Chatkin JM. Obesity and obstructive sleep apnea-hypopnea syndrome: the impact of bariatric surgery. Obes Surg. 2007;17(1):95-99.

219. Redenius R, Murphy C, O’Neill E, Al-Hamwi M, Zallek SN. Does CPAP lead to change in BMI. J Clin Sleep Med. 2008;4(3): 205-209.

220. Chin K, Shimizu K, Nakamura T, et al. Changes in intra-abdominal visceral fat and serum leptin levels in patients with obstructive sleep apnea syndrome following nasal continuous positive airway pressure therapy. Circulation. 1999;100(7):706-712.

221. Quan SF, Budhiraja R, Clarke DP, et al. Impact of treatment with continuous positive airway pressure (CPAP) on weight in obstructive sleep apnea. J Clin Sleep Med. 2013;9(10):989-993.

222. Stenlof K, Grunstein R, Hedner J, Sjostrom L. Energy expenditure in obstructive sleep apnea: effects of treatment with continuous positive airway pressure. Am J Physiol. 1996;271(6):E1036-E1043.

223. Peled N, Kassirer M, Shitrit D, et al. The association of OSA with insulin resistance, inflammation and metabolic syndrome. Respir Med. 2007;101(8):1696-1701.

224. Lindberg E, Theorell-Haglow J, Svensson M, Gislason T, Berne C, Janson C. Sleep apnea and glucose metabolism: a long-term follow-up in a community-based sample. Chest. 2012;142(4):935-942.

225. Punjabi NM, Beamer BA. Alterations in glucose disposal in sleep-disordered breathing. Am J Respir Crit Care Med. 2009;179(3):235-240

226. Elmasry A, Lindberg E, Berne C, et al. Sleep-disordered breathing and glucose metabolism in hypertensive men: a population-based study. $J$ Intern Med. 2001;249(2):153-161.

227. Fredheim JM, Rollheim J, Omland T, et al. Type 2 diabetes and prediabetes are associated with obstructive sleep apnea in extremely obese subjects: a cross-sectional study. Cardiovasc Diabetol. 2011;10:84.

228. Reichmuth KJ, Austin D, Skatrud JB, Young T. Association of sleep apnea and type II diabetes: a population-based study. Am J Respir Crit Care Med. 2005;172(12):1590-1595.

229. Marshall NS, Wong KK, Phillips CL, Liu PY, Knuiman MW, Grunstein RR. Is sleep apnea an independent risk factor for prevalent and incident diabetes in the Busselton Health Study? J Clin Sleep Med. 2009;5(1):15-20.

230. Botros N, Concato J, Mohsenin V, Selim B, Doctor K, Yaggi HK. Obstructive sleep apnea as a risk factor for type 2 diabetes. Am J Med. 2009;122(12):1122-1127.

231. Celen YT, Hedner J, Carlson J, Peker Y. Impact of gender on incident diabetes mellitus in obstructive sleep apnea: a 16-year follow-up. $J$ Clin Sleep Med. 2010;6(3):244-250.

232. Kendzerska T, Gershon AS, Hawker G, Tomlinson G, Leung RS. Obstructive sleep apnea and incident diabetes. A historical cohort study. Am J Respir Crit Care Med. 2014;190(2):218-225.

233. Foster GD, Sanders MH, Millman R, et al; Sleep AHEAD Research Group. Obstructive sleep apnea among obese patients with type 2 diabetes. Diabetes Care. 2009;32(6):1017-1019.

234. Shaw JE, Punjabi NM, Wilding JP, Alberti KG, Zimmet PZ, International Diabetes Federation Taskforce on Epidemiology and Prevention. Sleep-disordered breathing and type 2 diabetes: a report from the international diabetes federation taskforce on epidemiology and prevention. Diabetes Res Clin Pract. 2008;81(1):2-12

235. Harsch IA, Schahin SP, Radespiel-Troger M, et al. Continuous positive airway pressure treatment rapidly improves insulin sensitivity in patients with obstructive sleep apnea syndrome. Am J Respir Crit Care Med. 2004;169(2):156-162.

236. Harsch IA, Schahin SP, Bruckner K, et al. The effect of continuous positive airway pressure treatment on insulin sensitivity in patients with obstructive sleep apnoea syndrome and type 2 diabetes. Respiration. 2004;71(3):252-259.

237. Chirinos JA, Gurubhagavatula I, Teff K, et al. CPAP, weight loss, or both for obstructive sleep apnea. N Engl J Med. 2014;370(24):2265-2275.

238. Garcia JM, Sharafkhaneh H, Hirshkowitz M, Elkhatib R, Sharafkhaneh A. Weight and metabolic effects of CPAP in obstructive sleep apnea patients with obesity. Respir Res. 2011;12(1):80.
239. Guest JF, Panca M, Sladkevicius E, Taheri S, Stradling J. Clinical outcomes and cost-effectiveness of continuous positive airway pressure to manage obstructive sleep apnea in patients with type 2 diabetes in the U.K. Diabetes Care. 2014;37(5):1263-1271.

240. West SD, Nicoll DJ, Wallace TM, Matthews DR, Stradling JR. Effect of CPAP on insulin resistance and HbAlc in men with obstructive sleep apnoea and type 2 diabetes. Thorax. 2007;62(11): 969-974.

241. Martínez-Cerón E, Barquiel B, Bezos A-M, et al. Effect of CPAP on glycemic control in patients with obstructive sleep apnea and type 2 diabetes. A randomized clinical trial. Am J Respir Crit Care Med. Epub 2016 Feb 24.

242. Kapa S, Sert Kuniyoshi FH, Somers VK. Sleep apnea and hypertension: interactions and implications for management. Hypertension. 2008;51(3):605-608.

243. Nieto FJ, Young TB, Lind BK, et al. Association of sleep-disordered breathing, sleep apnea, and hypertension in a large community-based study. Sleep heart health study. JAMA. 2000;283(14):1829-1836.

244. Peppard PE, Young T, Palta M, Skatrud J. Prospective study of the association between sleep-disordered breathing and hypertension. $N$ Engl J Med. 2000;342(19):1378-1384.

245. Peker Y, Hedner J, Norum J, Kraiczi H, Carlson J. Increased incidence of cardiovascular disease in middle-aged men with obstructive sleep apnea: a 7-year follow-up. Am J Respir Crit Care Med. 2002;166(2):159-165.

246. Hla KM, Young TB, Bidwell T, Palta M, Skatrud JB, Dempsey J. Sleep apnea and hypertension. A population-based study. Ann Intern Med. 1994;120(5):382-388

247. Drager LF, Pereira AC, Barreto-Filho JA, et al. Phenotypic characteristics associated with hypertension in patients with obstructive sleep apnea. J Hum Hypertens. 2006;20(7):523-528.

248. Suzuki M, Guilleminault C, Otsuka K, Shiomi T. Blood pressure "dipping" and "non-dipping" in obstructive sleep apnea syndrome patients. Sleep. 1996;19(5):382-387.

249. Ashram YA, Abdel Wahab NH, Diab IH. Non-dipping pattern of nocturnal blood pressure in obstructive sleep apnea syndrome: possible role of oxidative stress and endothelin-1 precursor. Alexandria J Med. 2013;49(2):153-161.

250. Loredo JS, Ancoli-Israel S, Dimsdale JE. Sleep quality and blood pressure dipping in obstructive sleep apnea. Am J Hypertens. 2001;14(9):887-892.

251. Logan AG, Perlikowski SM, Mente A, et al. High prevalence of unrecognized sleep apnoea in drug-resistant hypertension. J Hypertens. 2001;19(12):2271-2277.

252. Pedrosa RP, Drager LF, Gonzaga CC, et al. Obstructive sleep apnea: the most common secondary cause of hypertension associated with resistant hypertension. Hypertension. 2011;58(5):811-817.

253. Haentjens P, Van Meerhaeghe A, Moscariello A, et al. The impact of continuous positive airway pressure on blood pressure in patients with obstructive sleep apnea syndrome: evidence from a metaanalysis of placebo-controlled randomized trials. Arch Intern Med. 2007;167(8):757-764.

254. Alajmi M, Mulgrew AT, Fox J, et al. Impact of continuous positive airway pressure therapy on blood pressure in patients with obstructive sleep apnea hypopnea: a meta-analysis of randomized controlled trials. Lung. 2007;185(2):67-72.

255. Bazzano LA, Khan Z, Reynolds K, He J. Effect of nocturnal nasal continuous positive airway pressure on blood pressure in obstructive sleep apnea. Hypertension. 2007;50(2):417-423.

256. Martinez-Garcia MA, Capote F, Campos-Rodriguez F, et al; Spanish Sleep Network. Effect of CPAP on blood pressure in patients with obstructive sleep apnea and resistant hypertension: the HIPARCO randomized clinical trial. JAMA. 2013;310(22):2407-2415.

257. Bratton DJ, Gaisl T, Wons AM, Kohler M. CPAP vs mandibular advancement devices and blood pressure in patients with obstructive sleep apnea: a systematic review and meta-analysis. JAMA. 2015;314(21):2280-2293. 
258. McArdle N, Hillman D, Beilin L, Watts G. Metabolic risk factors for vascular disease in obstructive sleep apnea: a matched controlled study. Am J Respir Crit Care Med. 2007;175(2):190-195.

259. Qian Y, Yi H, Zou J, et al. Independent association between sleep fragmentation and dyslipidemia in patients with obstructive sleep apnea. Sci Rep. 2016;6:26089.

260. Wu WT, Tsai SS, Shih TS, et al. The association between obstructive sleep apnea and metabolic markers and lipid profiles. PLoS One. 2015;10(6):e0130279.

261. Coughlin SR, Mawdsley L, Mugarza JA, Calverley PM, Wilding JP. Obstructive sleep apnoea is independently associated with an increased prevalence of metabolic syndrome. Eur Heart J. 2004;25(9):735-741.

262. Nadeem R, Singh M, Nida M, et al. Effect of obstructive sleep apnea hypopnea syndrome on lipid profile: a meta-regression analysis. JClin Sleep Med. 2014;10(5):475-489.

263. Cao Z, Zhang P, He Z, et al. Obstructive sleep apnea combined dyslipidemia render additive effect on increasing atherosclerotic cardiovascular diseases prevalence. Lipids Health Dis. 2016;15(1):98.

264. Gruber A, Horwood F, Sithole J, Ali NJ, Idris I. Obstructive sleep apnoea is independently associated with the metabolic syndrome but not insulin resistance state. Cardiovasc Diabetol. 2006;5:22.

265. Lam JC, Lam B, Lam CL, et al. Obstructive sleep apnea and the metabolic syndrome in community-based Chinese adults in Hong Kong. Respir Med. 2006;100(6):980-987.

266. Sasanabe R, Banno K, Otake K, et al. Metabolic syndrome in Japanese patients with obstructive sleep apnea syndrome. Hypertens Res. 2006;29(5):315-322.

267. Barreiro B, Garcia L, Lozano L, et al. Obstructive sleep apnea and metabolic syndrome in Spanish population. Open Respir Med J. 2013;7:71-76.

268. Minoguchi K, Yokoe T, Tazaki T, et al. Increased carotid intima-media thickness and serum inflammatory markers in obstructive sleep apnea. Am J Respir Crit Care Med. 2005;172(5):625-630.

269. Jelic S, Bartels MN, Mateika JH, Ngai P, DeMeersman RE, Basner RC. Arterial stiffness increases during obstructive sleep apneas. Sleep. 2002;25(8):850-855

270. Drakatos P, Higgins S, Pengo MF, et al. Derived arterial stiffness is increased in patients with obstructive sleep apnea and periodic limb movements during sleep. J Clin Sleep Med. 2016;12(2):195-202.

271. Seetho IW, Parker RJ, Craig S, Duffy N, Hardy KJ, Wilding JP. Obstructive sleep apnea is associated with increased arterial stiffness in severe obesity. J Sleep Res. 2014;23(6):700-708.

272. Gottlieb DJ, Yenokyan G, Newman AB, et al. Prospective study of obstructive sleep apnea and incident coronary heart disease and heart failure: the sleep heart health study. Circulation. 2010;122(4): 352-360.

273. Punjabi NM, Caffo BS, Goodwin JL, et al. Sleep-disordered breathing and mortality: a prospective cohort study. PLoS Med. 2009;6(8):e1000132.

274. Redline S, Yenokyan G, Gottlieb DJ, et al. Obstructive sleep apneahypopnea and incident stroke: the sleep heart health study. Am J Respir Crit Care Med. 2010;182(2):269-277.

275. Gami AS, Olson EJ, Shen WK, et al. Obstructive sleep apnea and the risk of sudden cardiac death: a longitudinal study of 10,701 adults. $J$ Am Coll Cardiol. 2013;62(7):610-616.

276. Dayyat E, Kheirandish-Gozal L, Gozal D. Childhood obstructive sleep apnea: one or two distinct disease entities? Sleep Med Clin. 2007;2(3):433-444.

277. Wang JH, Chung YS, Cho YW, et al. Palatine tonsil size in obese, overweight, and normal-weight children with sleep-disordered breathing. Otolaryngol Head Neck Surg. 2010;142(4):516-519.

278. Spilsbury JC, Storfer-Isser A, Rosen CL, Redline S. Remission and incidence of obstructive sleep apnea from middle childhood to late adolescence. Sleep. 2015;38(1):23-29.

279. Redline S, Tishler PV, Schluchter M, Aylor J, Clark K, Graham G. Risk factors for sleep-disordered breathing in children. Associations with obesity, race, and respiratory problems. Am J Respir Crit Care Med. 1999;159(5 pt 1):1527-1532.
280. Rudnick EF, Walsh JS, Hampton MC, Mitchell RB. Prevalence and ethnicity of sleep-disordered breathing and obesity in children. Otolaryngol Head Neck Surg. 2007;137(6):878-882.

281. Xu Z, Jiaqing A, Yuchuan L, Shen K. A case-control study of obstructive sleep apnea-hypopnea syndrome in obese and nonobese Chinese children. Chest. 2008;133(3):684-689.

282. Alonso-Alvarez ML, Cordero-Guevara JA, Teran-Santos J, et al. Obstructive sleep apnea in obese community-dwelling children: the NANOS study. Sleep. 2014;37(5):943-949.

283. Canapari CA, Hoppin AG, Kinane TB, Thomas BJ, Torriani M, Katz ES. Relationship between sleep apnea, fat distribution, and insulin resistance in obese children. J Clin Sleep Med. 2011;7(3):268-273.

284. Kohler MJ, Thormaehlen S, Kennedy JD, et al. Differences in the association between obesity and obstructive sleep apnea among children and adolescents. J Clin Sleep Med. 2009;5(6):506-511.

285. Kaditis AG, Alexopoulos EI, Hatzi F, et al. Adiposity in relation to age as predictor of severity of sleep apnea in children with snoring. Sleep Breath. 2008;12(1):25-31.

286. Kalra M, Inge $\mathrm{T}$, Garcia $\mathrm{V}$, et al. Obstructive sleep apnea in extremely overweight adolescents undergoing bariatric surgery. Obes Res. 2005;13(7):1175-1179.

287. Kaditis AG, Alexopoulos EI, Damani E, et al. Obstructive sleepdisordered breathing and fasting insulin levels in nonobese children. Pediatr Pulmonol. 2005;40(6):515-523.

288. Tauman R, O'Brien LM, Ivanenko A, Gozal D. Obesity rather than severity of sleep-disordered breathing as the major determinant of insulin resistance and altered lipidemia in snoring children. Pediatrics. 2005;116(1):e66-e73.

289. Gozal D, Capdevila OS, Kheirandish-Gozal L. Metabolic alterations and systemic inflammation in obstructive sleep apnea among nonobese and obese prepubertal children. Am J Respir Crit Care Med. 2008;177(10):1142-1149.

290. Li AM, Chan MH, Chan DF, et al. Insulin and obstructive sleep apnea in obese Chinese children. Pediatr Pulmonol. 2006;41(12):1175-1181.

291. Hannon TS, Lee S, Chakravorty S, Lin YAN, Arslanian SA. Sleepdisordered breathing in obese adolescents is associated with visceral adiposity and markers of insulin resistance. Int J Pediatr Obes. 2011;6(2):157-160

292. de la Eva RC, Baur LA, Donaghue KC, Waters KA. Metabolic correlates with obstructive sleep apnea in obese subjects. $J$ Pediatr. 2002;140(6):654-659.

293. Redline S, Storfer-Isser A, Rosen CL, et al. Association between metabolic syndrome and sleep-disordered breathing in adolescents. Am J Respir Crit Care Med. 2007;176(4):401-408.

294. Lesser DJ, Bhatia R, Tran WH, et al. Sleep fragmentation and intermittent hypoxemia are associated with decreased insulin sensitivity in obese adolescent Latino males. Pediatr Res. 2012;72(3):293-298.

295. Kelly A, Dougherty S, Cucchiara A, Marcus CL, Brooks LJ. Catecholamines, adiponectin, and insulin resistance as measured by HOMA in children with obstructive sleep apnea. Sleep. 2010;33(9): 1185-1191.

296. Bhushan B, Maddalozzo J, Sheldon SH, et al. Metabolic alterations in children with obstructive sleep apnea. Int J Pediatr Otorhinolaryngol. 2014;78(5):854-859.

297. Shamsuzzaman A, Szczesniak RD, Fenchel MC, Amin RS. Glucose, insulin, and insulin resistance in normal-weight, overweight and obese children with obstructive sleep apnea. Obes Res Clin Pract. 2014; 8(6):e584-e591.

298. Koren D, Gozal D, Bhattacharjee R, Philby M, Kheirandish-Gozal L. Impact of adenotonsillectomy on insulin resistance and lipoprotein profile in nonobese and obese children. Chest. 2016;149(4):999-1010.

299. Waters KA, Sitha S, O'Brien LM, et al. Follow-up on metabolic markers in children treated for obstructive sleep apnea. Am J Respir Crit Care Med. 2006;174(4):455-460.

300. Bhushan B, Ayub B, Loghmanee DA, Billings KR. Metabolic alterations in adolescents with obstructive sleep apnea. Int J Pediatr Otorhinolaryngol. 2015;79(12):2368-2373. 
301. Shalitin S, Tauman R, Meyerovitch J, Sivan Y. Are frequency and severity of sleep-disordered breathing in obese children and youth with and without type 2 diabetes mellitus different? Acta Diabetol. 2014;51(5):757-764.

302. Kaditis AG, Alexopoulos EI, Kostadima E, et al. Comparison of blood pressure measurements in children with and without habitual snoring. Pediatr Pulmonol. 2005;39(5):408-414.

303. Amin RS, Carroll JL, Jeffries JL, et al. Twenty-four-hour ambulatory blood pressure in children with sleep-disordered breathing. Am J Respir Crit Care Med. 2004;169(8):950-956.

304. Leung LC, Ng DK, Lau MW, et al. Twenty-four-hour ambulatory BP in snoring children with obstructive sleep apnea syndrome. Chest. 2006;130(4):1009-1017.

305. Enright PL, Goodwin JL, Sherrill DL, Quan JR, Quan SF; Tucson Children's Assessment of Sleep Apnea Study. Blood pressure elevation associated with sleep-related breathing disorder in a community sample of white and Hispanic children: the Tucson Children's Assessment of Sleep Apnea study. Arch Pediatr Adolesc Med. 2003;157(9):901-904.

306. Li AM, Au CT, Sung RY, et al. Ambulatory blood pressure in children with obstructive sleep apnoea - a community based study. Thorax. 2008;63(9):803-809.

307. Marcus CL, Greene MG, Carroll JL. Blood pressure in children with obstructive sleep apnea. Am J Respir Crit Care Med. 1998;157(4 pt 1): 1098-1103.

308. Ng DK, Wong JC, Chan CH, Leung LC, Leung SY. Ambulatory blood pressure before and after adenotonsillectomy in children with obstructive sleep apnea. Sleep Med. 2010;11(7):721-725.

309. Apostolidou MT, Alexopoulos EI, Damani E, et al. Absence of blood pressure, metabolic, and inflammatory marker changes after adenotonsillectomy for sleep apnea in Greek children. Pediatr Pulmonol. 2008;43(6):550-560.

310. Quante M, Wang R, Weng J, et al; Childhood Adenotonsillectomy Trial (CHAT). The effect of adenotonsillectomy for childhood sleep apnea on cardiometabolic measures. Sleep. 2015;38(9):1395-1403.

311. Suri JC, Sen MK, Sharma R, Chakrabarti S, Mir E, Adhikari T. Metabolic changes in normal- and underweight children with obstructive sleep-disordered breathing. Sleep Med. 2015;16(11):1366-1371.

312. Alexopoulos EI, Gletsou E, Kostadima E, et al. Effects of obstructive sleep apnea severity on serum lipid levels in Greek children with snoring. Sleep Breath. 2011;15(4):625-631.

313. Nakra N, Bhargava S, Dzuira J, Caprio S, Bazzy-Asaad A. Sleepdisordered breathing in children with metabolic syndrome: the role of leptin and sympathetic nervous system activity and the effect of continuous positive airway pressure. Pediatrics. 2008;122(3): e634-e642.

314. Verhulst SL, Schrauwen N, Haentjens D, et al. Sleep-disordered breathing and the metabolic syndrome in overweight and obese children and adolescents. J Pediatr. 2007;150(6):608-612.

315. Jalilolghadr S, Yazdi Z, Mahram M, et al. Sleep architecture and obstructive sleep apnea in obese children with and without metabolic syndrome: a case control study. Sleep Breath. 2016;20(2):845-851.

316. Xu S, Wan Y, Xu M, et al. The association between obstructive sleep apnea and metabolic syndrome: a systematic review and meta-analysis. BMC Pulm Med. 2015;15:105.

317. Erdim I, Akcay T, Yilmazer R, Erdur O, Kayhan FT. Is metabolic syndrome associated with obstructive sleep apnea in obese adolescents? J Clin Sleep Med. 2015;11(12):1371-1376.

318. Freedman DS, Khan LK, Dietz WH, Srinivasan SR, Berenson GS. Relationship of childhood obesity to coronary heart disease risk factors in adulthood: the Bogalusa Heart Study. Pediatrics. 2001;108(3):712-718.

319. Tounian P, Aggoun Y, Dubern B, et al. Presence of increased stiffness of the common carotid artery and endothelial dysfunction in severely obese children: a prospective study. Lancet. 2001;358(9291):1400-1404.

320. Meyer AA, Kundt G, Steiner M, Schuff-Werner P, Kienast W. Impaired flow-mediated vasodilation, carotid artery intima-media thickening, and elevated endothelial plasma markers in obese children: the impact of cardiovascular risk factors. Pediatrics. 2006;117(5):1560-1567.
321. Iannuzzi A, Licenziati MR, Vacca M, et al. Comparison of two diets of varying glycemic index on carotid subclinical atherosclerosis in obese children. Heart Vessels. 2009;24(6):419-424.

322. Iannuzzi A, Licenziati MR, Acampora C, et al. Increased carotid intima-media thickness and stiffness in obese children. Diabetes Care. 2004;27(10):2506-2508.

323. Urbina EM, Kimball TR, McCoy CE, Khoury PR, Daniels SR, Dolan LM. Youth with obesity and obesity-related type 2 diabetes mellitus demonstrate abnormalities in carotid structure and function. Circulation. 2009;119(22):2913-2919.

324. Gozal D, Kheirandish-Gozal L, Bhattacharjee R, Spruyt K. Neurocognitive and endothelial dysfunction in children with obstructive sleep apnea. Pediatrics. 2010;126(5):e1161-e1167.

325. Gozal D, Kheirandish-Gozal L, Serpero LD, Sans Capdevila O, Dayyat E. Obstructive sleep apnea and endothelial function in schoolaged nonobese children: effect of adenotonsillectomy. Circulation. 2007;116(20):2307-2314.

326. Bhattacharjee R, Kim J, Alotaibi WH, Kheirandish-Gozal L, Capdevila OS, Gozal D. Endothelial dysfunction in children without hypertension: potential contributions of obesity and obstructive sleep apnea. Chest. 2012;141(3):682-691.

327. Dubern B, Aggoun Y, Boule M, Fauroux B, Bonnet D, Tounian P. Arterial alterations in severely obese children with obstructive sleep apnoea. Int J Pediatr Obes. 2010;5(3):230-236.

328. Iannuzzi A, Licenziati MR, De Michele F, et al. C-reactive protein and carotid intima-media thickness in children with sleep disordered breathing. J Clin Sleep Med. 2013;9(5):493-498.

329. Koren D, Chirinos JA, Katz LE, et al. Interrelationships between obesity, obstructive sleep apnea syndrome and cardiovascular risk in obese adolescents. Int J Obes (Lond). 2015;39(7):1086-1093.

330. Ciftel M, Demir B, Kozan G, Yilmaz O, Kahveci H, Kilic O. Evaluation of carotid intima-media thickness and carotid arterial stiffness in children with adenotonsillar hypertrophy. World J Pediatr. 2016;12(1):103-108.

331. Indra N, Brian M, Suhail A-S, et al. Obstructive sleep apnea and vascular stiffness in obese adolescents. In: A27. Advances in Pediatric Sleep; American Thoracic Society; 2016:A1221-A1221; San Francisco, CA

332. Tal A, Leiberman A, Margulis G, Sofer S. Ventricular dysfunction in children with obstructive sleep apnea: radionuclide assessment. Pediatr Pulmonol. 1988;4(3):139-143.

333. Spath-Schwalbe E, Gofferje M, Kern W, Born J, Fehm HL. Sleep disruption alters nocturnal ACTH and cortisol secretory patterns. Biol Psychiatry. 1991;29(6):575-584.

334. Buckley TM, Schatzberg AF. On the interactions of the hypothalamicpituitary-adrenal (HPA) axis and sleep: normal HPA axis activity and circadian rhythm, exemplary sleep disorders. J Clin Endocrinol Metab. 2005;90(5):3106-3114

335. Shamsuzzaman AS, Winnicki M, Lanfranchi P, et al. Elevated C-reactive protein in patients with obstructive sleep apnea. Circulation. 2002;105(21):2462-2464.

336. Yokoe T, Minoguchi K, Matsuo H, et al. Elevated levels of C-reactive protein and interleukin- 6 in patients with obstructive sleep apnea syndrome are decreased by nasal continuous positive airway pressure. Circulation. 2003;107(8):1129-1134.

337. Nadeem R, Molnar J, Madbouly EM, et al. Serum inflammatory markers in obstructive sleep apnea: a meta-analysis. J Clin Sleep Med. 2013;9(10):1003-1012.

338. Drager LF, Lopes HF, Maki-Nunes C, et al. The impact of obstructive sleep apnea on metabolic and inflammatory markers in consecutive patients with metabolic syndrome. PLoS One. 2010;5(8):e12065.

339. Sharma S, Malur A, Marshall I, et al. Alveolar macrophage activation in obese patients with obstructive sleep apnea. Surgery. 2012;151(1):107-112.

340. Baessler A, Nadeem R, Harvey M, et al. Treatment for sleep apnea by continuous positive airway pressure improves levels of inflammatory markers - a meta-analysis. J Inflamm (Lond). 2013;10:13.

341. Vgontzas AN, Zoumakis E, Bixler EO, et al. Selective effects of CPAP on sleep apnoea-associated manifestations. Eur J Clin Invest. 2008;38(8):585-595. 
342. Schwab RJ, Pasirstein M, Pierson R, et al. Identification of upper airway anatomic risk factors for obstructive sleep apnea with volumetric magnetic resonance imaging. Am J Respir Crit Care Med. 2003;168(5):522-530.

343. Pillar G, Shehadeh N. Abdominal fat and sleep apnea: the chicken or the egg? Diabetes Care. 2008;31(suppl 2):S303-S309.

344. Naimark A, Cherniack RM. Compliance of the respiratory system and its components in health and obesity. $J$ Appl Physiol. 1960;15: 377-382.

345. Sakurai S, Nishijima T, Takahashi S, Yamauchi K, Arihara Z, Takahashi $\mathrm{K}$. Low plasma orexin-A levels were improved by continuous positive airway pressure treatment in patients with severe obstructive sleep apnea-hypopnea syndrome. Chest. 2005;127(3):731-737.

346. Harsch IA, Konturek PC, Koebnick C, et al. Leptin and ghrelin levels in patients with obstructive sleep apnoea: effect of CPAP treatment. Eur Resp J. 2003;22.

347. Phillips BG, Kato M, Narkiewicz K, Choe I, Somers VK. Increases in leptin levels, sympathetic drive, and weight gain in obstructive sleep apnea. Am J Physiol Heart Circ Physiol. 2000;279(1):H234-237.

348. Tachikawa R, Ikeda K, Minami T, et al. Changes in energy metabolism after continuous positive airway pressure for obstructive sleep apnea. Am J Respir Crit Care Med. Epub 2016 Mar 1.

349. Munzer T, Hegglin A, Stannek T, et al. Effects of long-term continuous positive airway pressure on body composition and IGF1. Eur $J$ Endocrinol. 2010;162(4):695-704.

350. Batool-Anwar S, Goodwin JL, Drescher AA, et al. Impact of CPAP on activity patterns and diet in patients with obstructive sleep apnea (OSA). J Clin Sleep Med. 2014;10(5):465-472.

351. Iiyori $\mathrm{N}$, Alonso $\mathrm{LC}, \mathrm{Li} \mathrm{J}$, et al. Intermittent hypoxia causes insulin resistance in lean mice independent of autonomic activity. Am J Respir Crit Care Med. 2007;175(8):851-857.

352. Stamatakis KA, Punjabi NM. Effects of sleep fragmentation on glucose metabolism in normal subjects. Chest. 2010;137(1):95-101.

353. Marcus CL, Brooks LJ, Draper KA, et al; American Academy of Pediatrics. Diagnosis and management of childhood obstructive sleep apnea syndrome. Pediatrics. 2012;130(3):e714-e755.

354. Tauman R, O'Brien LM, Gozal D. Hypoxemia and obesity modulate plasma C-reactive protein and interleukin-6 levels in sleep-disordered breathing. Sleep Breath. 2007;11(2):77-84.

355. O'Brien LM, Gozal D. Autonomic dysfunction in children with sleepdisordered breathing. Sleep. 2005;28(6):747-752.

356. Tauman R, Serpero LD, Capdevila OS, et al. Adipokines in children with sleep disordered breathing. Sleep. 2007;30(4):443-449.

357. Oltmanns KM, Gehring H, Rudolf S, et al. Hypoxia Causes Glucose Intolerance in Humans. Am J Respir Crit Care Med. 2004;169(11):1231-1237.

358. Brooks B, Cistulli PA, Borkman M, et al. Obstructive sleep apnea in obese noninsulin-dependent diabetic patients: effect of continuous positive airway pressure treatment on insulin responsiveness. $J$ Clin Endocrinol Metab. 1994;79(6):1681-1685.

359. Lam JCM, Xu A, Tam S, et al. Hypoadiponectinemia is related to sympathetic activation and severity of obstructive sleep apnea. Sleep. 2008;31(12):1721-1727.

360. Martinez-Ceron E, Barquiel B, Bezos AM, et al. Effect of CPAP on glycemic control in patients with obstructive sleep apnea and type 2 diabetes. a randomized clinical trial. Am J Resp Crit Care Med. 2016.

361. Monneret D, Tamisier R, Ducros V, et al. Glucose tolerance and cardiovascular risk biomarkers in non-diabetic non-obese obstructive sleep apnea patients: effects of long-term continuous positive airway pressure. Resp Med. 2016;112:119-125.

362. Pamidi S, Wroblewski K, Stepien M, et al. Eight hours of nightly continuous positive airway pressure treatment of obstructive sleep apnea improves glucose metabolism in patients with prediabetes. a randomized controlled trial. Am J Resp Crit Care Med. 2015;192(1): 96-105.

363. Shaw JE, Punjabi NM, Naughton MT, et al. The effect of treatment of obstructive sleep apnea on glycemic control in type 2 diabetes. Am J Respir Crit Care Med. Epub 2016 Feb 29.
364. Fletcher EC, Miller J, Schaaf JW, Fletcher JG. Urinary catecholamines before and after tracheostomy in patients with obstructive sleep apnea and hypertension. Sleep. 1987;10(1):35-44.

365. Waradekar NV, Sinoway LI, Zwillich CW, Leuenberger UA. Influence of treatment on muscle sympathetic nerve activity in sleep apnea. $A m$ J Respir Crit Care Med. 1996;153(4 pt 1):1333-1338.

366. Somers VK, Dyken ME, Mark AL, Abboud FM. Sympatheticnerve activity during sleep in normal subjects. $N$ Engl $J$ Med. 1993;328(5):303-307.

367. Somers VK, Mark AL, Zavala DC, Abboud FM. Contrasting effects of hypoxia and hypercapnia on ventilation and sympathetic activity in humans. J Appl Physiol (1985). 1989;67(5):2101-2106.

368. Di Murro A, Petramala L, Cotesta D, et al. Renin-angiotensin-aldosterone system in patients with sleep apnoea: prevalence of primary aldosteronism. J Renin Angiotensin Aldosterone Syst. 2010;11(3):165-172.

369. Calbet JA. Chronic hypoxia increases blood pressure and noradrenaline spillover in healthy humans. $J$ Physiol. 2003;551(pt 1):379-386.

370. Foster GE, Hanly PJ, Ahmed SB, Beaudin AE, Pialoux V, Poulin MJ. Intermittent hypoxia increases arterial blood pressure in humans through a renin-angiotensin system-dependent mechanism. Hypertension. 2010;56(3):369-377.

371. Becker HF, Jerrentrup A, Ploch T, et al. Effect of nasal continuous positive airway pressure treatment on blood pressure in patients with obstructive sleep apnea. Circulation. 2003;107(1):68-73.

372. Hoyos CM, Yee BJ, Wong KK, Grunstein RR, Phillips CL. Treatment of sleep apnea with CPAP lowers central and peripheral blood pressure independent of the time-of-day: a randomized controlled study. $A m \mathrm{~J}$ Hypertens. 2015;28(10):1222-1228.

373. Kario K. Obstructive sleep apnea syndrome and hypertension: mechanism of the linkage and 24-h blood pressure control. Hypertens Res. 2009;32(7):537-541.

374. Faccenda JF, Mackay TW, Boon NA, Douglas NJ. Randomized placebo-controlled trial of continuous positive airway pressure on blood pressure in the sleep apnea-hypopnea syndrome. Am J Respir Crit Care Med. 2001;163(2):344-348.

375. Li J, Thorne LN, Punjabi NM, et al. Intermittent hypoxia induces hyperlipidemia in lean mice. Circ Res. 2005;97(7):698-706.

376. Li J, Savransky V, Nanayakkara A, Smith PL, O’Donnell CP, Polotsky VY. Hyperlipidemia and lipid peroxidation are dependent on the severity of chronic intermittent hypoxia. J Appl Physiol (1985). 2007;102(2):557-563.

377. Li J, Grigoryev DN, Ye SQ, et al. Chronic intermittent hypoxia upregulates genes of lipid biosynthesis in obese mice. JAppl Physiol (1985). 2005;99(5):1643-1648.

378. Savransky V, Nanayakkara A, Li J, et al. Chronic intermittent hypoxia induces atherosclerosis. Am J Respir Crit Care Med. 2007;175(12): 1290-1297.

379. Lavie L. Oxidative stress inflammation and endothelial dysfunction in obstructive sleep apnea. Front Biosci (Elite Ed). 2012;4:1391-1403.

380. Adedayo AM, Olafiranye O, Smith D, et al. Obstructive sleep apnea and dyslipidemia: evidence and underlying mechanism. Sleep Breath. 2014;18(1):13-18.

381. Mirrakhimov AE, Ali AM. Pathobiology of obstructive sleep apnea-related dyslipidemia: focus on the liver. ISRN Cardiol. 2013; 2013:687069.

382. Barcelo A, Pierola J, de la Pena M, et al. Free fatty acids and the metabolic syndrome in patients with obstructive sleep apnoea. Eur Respir J. 2011;37(6):1418-1423.

383. Jun JC, Drager LF, Najjar SS, et al. Effects of sleep apnea on nocturnal free fatty acids in subjects with heart failure. Sleep. 2011; 34(9):1207-1213.

384. Jun JC, Shin MK, Yao Q, et al. Acute hypoxia induces hypertriglyceridemia by decreasing plasma triglyceride clearance in mice. $\mathrm{Am} \mathrm{J}$ Physiol Endocrinol Metab. 2012;303(3):E377-E388.

385. Keenan BT, Maislin G, Sunwoo BY, et al. Obstructive sleep apnoea treatment and fasting lipids: a comparative effectiveness study. Eur Respir J. 2014;44(2):405-414. 
386. Sharma SK, Agrawal S, Damodaran D, et al. CPAP for the metabolic syndrome in patients with obstructive sleep apnea. $N$ Engl J Med. 2011;365(24):2277-2286.

387. Kato M, Roberts-Thomson P, Phillips BG, et al. Impairment of endothelium-dependent vasodilation of resistance vessels in patients with obstructive sleep apnea. Circulation. 2000;102(21):2607-2610.

388. Kraiczi H, Caidahl K, Samuelsson A, Peker Y, Hedner J. Impairment of vascular endothelial function and left ventricular filling: association with the severity of apnea-induced hypoxemia during sleep. Chest 2001;119(4):1085-1091.

389. Imadojemu VA, Gleeson K, Quraishi SA, Kunselman AR, Sinoway LI, Leuenberger UA. Impaired vasodilator responses in obstructive sleep apnea are improved with continuous positive airway pressure therapy. Am J Respir Crit Care Med. 2002;165(7):950-953.

390. Ip MSM, Tse H-F, Lam B, Tsang KWT, Lam W-K. Endothelial function in obstructive sleep apnea and response to treatment. Am J Respir Crit Care Med. 2004;169(3):348-353.

391. Kohler M, Stoewhas AC, Ayers L, et al. Effects of continuous positive airway pressure therapy withdrawal in patients with obstructive sleep apnea: a randomized controlled trial. Am J Respir Crit Care Med. 2011;184(10):1192-1199.

392. Dyugovskaya L, Lavie P, Lavie L. Lymphocyte activation as a possible measure of atherosclerotic risk in patients with sleep apnea. Ann $N Y$ Acad Sci. 2005;1051:340-350.

393. Yun C-H, Jung K-H, Chu K, et al. Increased circulating endothelial microparticles and carotid atherosclerosis in obstructive sleep apnea. J Clin Neurol. 2010;6(2):89-98.

394. Jose MM, Teresa M, Victoria G, Pablo C, Marta F, Ana LS. Long-term effect of CPAP on subclinical atherosclerosis in obstructive sleep apnea. In: D98. After Serve-HF: Now What? American Thoracic Society; 2016:A7534-A7534; San Francisco, CA.

395. Chami HA, Vasan RS, Larson MG, Benjamin EJ, Mitchell GF, Gottlieb DJ. The association between sleep-disordered breathing and aortic stiffness in a community cohort. Sleep Med. 2016;19:69-74.

396. Drager LF, Bortolotto LA, Figueiredo AC, Krieger EM, Lorenzi GF. Effects of continuous positive airway pressure on early signs of atherosclerosis in obstructive sleep apnea. Am J Respir Crit Care Med. 2007;176(7):706-712.

397. Buchner NJ, Quack I, Stegbauer J, Woznowski M, Kaufmann A, Rump LC. Treatment of obstructive sleep apnea reduces arterial stiffness. Sleep Breath. 2012;16(1):123-133.

398. Vlachantoni IT, Dikaiakou E, Antonopoulos CN, Stefanadis C, Daskalopoulou SS, Petridou ET. Effects of continuous positive airway pressure (CPAP) treatment for obstructive sleep apnea in arterial stiffness: a meta-analysis. Sleep Med Rev. 2013;17(1): $19-28$.

399. Lin X, Chen G, Qi J, Chen X, Zhao J, Lin Q. Effect of continuous positive airway pressure on arterial stiffness in patients with obstructive sleep apnea and hypertension: a meta-analysis. Eur Arch Otorhinolaryngol. Epub 2016 Feb 9:1-8.

400. Shiina K, Tomiyama H, Takata Y, et al. Effects of CPAP therapy on the sympathovagal balance and arterial stiffness in obstructive sleep apnea. Respir Med. 2010;104(6):911-916.

401. Peker Y, Carlson J, Hedner J. Increased incidence of coronary artery disease in sleep apnoea: a long-term follow-up. Eur Respir J. 2006;28(3):596-602.

402. Milleron O, Pilliere R, Foucher A, et al. Benefits of obstructive sleep apnoea treatment in coronary artery disease: a long-term follow-up study. Eur Heart J. 2004;25(9):728-734.

403. Somers VK, White DP, Amin R, et al. Sleep Apnea and Cardiovascular Disease: an American Heart Association/American College of Cardiology Foundation Scientific Statement From the American Heart Association Council for High Blood Pressure Research Professional Education Committee, Council on Clinical Cardiology, Stroke Council, and Council on Cardiovascular Nursing in Collaboration With the National Heart, Lung, and Blood Institute National Center on Sleep Disorders Research (National Institutes of Health). Circulation. 2008;118(10): $1080-1111$.
404. Marcus CL, Moore RH, Rosen CL, et al; Childhood Adenotonsillectomy Trial (CHAT). A randomized trial of adenotonsillectomy for childhood sleep apnea. N Engl J Med. 2013;368(25):2366-2376.

405. Nakra N, Bhargava S, Dzuira J, Caprio S, Bazzy-Asaad A. Sleepdisordered breathing in children with metabolic syndrome: the role of leptin and sympathetic nervous system activity and the effect of continuous positive airway pressure. Pediatrics. 2008;122(3): e634-642.

406. Karalok ZS, Akdag M, Turhan M, et al. Leptin and ghrelin levels in children before and after adenoidectomy or adenotonsillectomy. Horm Res Paediatr. 2014;81(1):20-24.

407. Salman N, Ozturk G, Akin I, Kilicaslan S, Demirel F, Delibas N. The effect of adenotonsilectomy on ghrelin, leptin, IGF-1 levels and growth parameters in children with adenotonsillar hypertrophy. $J$ Pediatr Endocrinol Metab. 2014;27(9-10):885-890.

408. Katz ES, Moore RH, Rosen CL, et al. Growth after adenotonsillectomy for obstructive sleep apnea: an RCT. Pediatrics. 2014;134(2): 282-289.

409. Levi J, Leoniak S, Schmidt R. Evaluating tonsillectomy as a risk factor for childhood obesity. Arch Otolaryngol Head Neck Surg. 2012;138(10):897-901.

410. Deboer MD, Mendoza JP, Liu L, Ford G, Yu PL, Gaston BM. Increased systemic inflammation overnight correlates with insulin resistance among children evaluated for obstructive sleep apnea. Sleep Breath. 2012;16(2):349-354

411. Gozal D. Sleep, sleep disorders and inflammation in children. Sleep Med. 2009;10(suppl 1):S12-S16.

412. Hakim F, Gozal D, Kheirandish-Gozal L. Sympathetic and catecholaminergic alterations in sleep apnea with particular emphasis on children. Front Neurol. 2012;3:7.

413. Aljadeff G, Gozal D, Schechtman VL, Burrell B, Harper RM, Ward SL. Heart rate variability in children with obstructive sleep apnea. Sleep. 1997;20(2):151-157.

414. Lafortuna CL, Adorni F, Agosti F, et al. Prevalence of the metabolic syndrome among extremely obese adolescents in Italy and Germany. Diabetes Res Clin Pract. 2010;88(1):14-21.

415. Gozal D, Hakim F, Kheirandish-Gozal L. Chemoreceptors, baroreceptors, and autonomic deregulation in children with obstructive sleep apnea. Respir Physiol Neurobiol. 2013;185(1):177-185.

416. Gozal D, Capdevila OS, Kheirandish-Gozal L. Metabolic alterations and systemic inflammation in obstructive sleep apnea among nonobese and obese prepubertal children. Am J Respir Crit Care Med. 2008;177(10):1142-1149.

417. Kuo YL, Kang KT, Chiu SN, Weng WC, Lee PL, Hsu WC. Blood pressure after surgery among obese and nonobese children with obstructive sleep apnea. Otolaryngol Head Neck Surg. 2015;152(5):931-940.

418. Gozal D, Serpero LD, Sans Capdevila O, Kheirandish-Gozal L. Systemic inflammation in non-obese children with obstructive sleep apnea. Sleep Med. 2008;9(3):254-259.

419. Kheirandish-Gozal L, Gileles-Hillel A, Alonso-Alvarez ML, et al. Effects of adenotonsillectomy on plasma inflammatory biomarkers in obese children with obstructive sleep apnea: a community-based study. Int J Obes (Lond). 2015;39(7):1094-1100.

420. Nachalon Y, Lowenthal N, Greenberg-Dotan S, Goldbart AD. Inflammation and growth in young children with obstructive sleep apnea syndrome before and after adenotonsillectomy. Mediators Inflamm. 2014;2014:146893.

421. Kheirandish-Gozal L, Bhattacharjee R, Kim J, Clair HB, Gozal D. Endothelial progenitor cells and vascular dysfunction in children with obstructive sleep apnea. Am J Respir Crit Care Med. 2010;182(1):92-97.

422. Abdelnaby K, Leila K-G, Maria Luz A-A, Joaquin T-S, David G Plasma-derived exosomes alter endothelial tight junction in obese children with obstructive sleep apnea: effect of adenotonsillectomy (T\&A). In: B26. Pediatric Sleep: From the Heart to the Brain; American Thoracic Society; 2015:A2596-A2596; Denver, CO.

423. Kheirandish-Gozal L, Etzioni T, Bhattacharjee R, et al. Obstructive sleep apnea in children is associated with severity-dependent deterioration in overnight endothelial function. Sleep Med. 2013;14(6):526-531. 
424. Ruger M, Scheer FA. Effects of circadian disruption on the cardiometabolic system. Rev Endocr Metab Disord. 2009;10(4): 245-260.

425. Morris CJ, Aeschbach D, Scheer FAJL. Circadian system, sleep and endocrinology. Mol Cell Endocrinol. 2012;349(1):91-104.

426. Reutrakul S, Van Cauter E. Interactions between sleep, circadian function, and glucose metabolism: implications for risk and severity of diabetes. Ann NY Acad Sci. 2014;1311:151-173.

427. Morris CJ, Yang JN, Scheer FA. The impact of the circadian timing system on cardiovascular and metabolic function. Prog Brain Res. 2012;199:337-358.

428. Karlsson B, Knutsson A, Lindahl B. Is there an association between shift work and having a metabolic syndrome? Results from a population based study of 27,485 people. Occup Environ Med. 2001;58(11): 747-752.

429. Lund J, Arendt J, Hampton SM, English J, Morgan LM. Postprandial hormone and metabolic responses among shift workers in Antarctica. J Endocrinol. 2001;171:557-564.

430. Morikawa Y, Nakagawa H, Miura K, et al. Shift work and the risk of diabetes mellitus among Japanese male factory workers. Scand JWork Environ Health. 2005;31(3):179-183.

431. Kroenke CH, Spiegelman D, Manson J, Schernhammer ES, Colditz GA, Kawachi I. Work characteristics and incidence of type 2 diabetes in women. Am J Epidemiol. 2007;165(2):175-183.

432. Knutsson A, Akerstedt T, Jonsson BG, Orth-Gomer K. Increased risk of ischaemic heart disease in shift workers. Lancet. 1986;2(8498): 89-92.

433. Merikanto I, Lahti T, Puolijoki H, et al. Associations of chronotype and sleep with cardiovascular diseases and type 2 diabetes. Chronobiol Int. 2013;30(4):470-477.

434. Reutrakul S, Hood MM, Crowley SJ, et al. Chronotype is independently associated with glycemic control in type 2 diabetes. Diabetes Care. 2013;36(9):2523-2529.

435. Lucassen EA, Zhao X, Rother KI, et al; Sleep Extension Study Group. Evening chronotype is associated with changes in eating behavior, more sleep apnea, and increased stress hormones in short sleeping obese individuals. PLoS One. 2013;8(3):e56519.

436. Arora T, Taheri S. Associations among late chronotype, body mass index and dietary behaviors in young adolescents. Int J Obes (Lond). 2015;39(1):39-44.

437. Fleig D, Randler C. Association between chronotype and diet in adolescents based on food logs. Eat Behav. 2009;10(2):115-118.
438. Salgado-Delgado R, Angeles-Castellanos M, Buijs MR, Escobar C. Internal desynchronization in a model of night-work by forced activity in rats. Neuroscience. 2008;154(3):922-931.

439. Arble D, Bass J, Laposky AD, Vitaterna MH, Turek FW. Circadian timing of food intake contributes to weight gain. Obesity (Silver Spring). 2009;17(11):2100-2102.

440. Fonken LK, Workman JL, Walton JC, et al. Light at night increases body mass by shifting the time of food intake. Proc Natl Acad Sci U S A. 2010;107(43):18664-18669.

441. Turek FW, Joshu C, Kohsaka A, et al. Obesity and metabolic syndrome in circadian clock mutant mice. Science. 2005;308(5724):1043-1045.

442. Hampton SM, Morgan LM, Lawrence N, et al. Postprandial hormone and metabolic responses in simulated shift work. $J$ Endocrinol. 1996;151(2):259-267.

443. Ribeiro D, Hampton SM, Morgan L, Deacon S, Arendt J. Altered postprandial hromone and metabolic responses in a simulated shift work environment. J Endocrinol. 1998;158:305-310.

444. Scheer FA, Hitlon MF, Mantzoros CS, Shea SA. Adverse metabolic and cardiovascular consequences of circadian misalignment. Proc Natl Acad Sci US A. 2009;106(11):4453-4458.

445. Beebe DW, Zhou A, Rausch J, Noe O, Simon SL. The impact of early bedtimes on adolescent caloric intake varies by chronotype. JAdolesc Health. 2015;57(1):120-122.

446. Van Cauter E, Blackman JD, Roland D, Spire JP, Refetoff S, Polonsky KS. Modulation of glucose regulation and insulin secretion by circadian rhythmicity and sleep. J Clin Invest. 1991;88(3):934-942.

447. Simon C, Gronfier C, Schlienger JL, Brandenberger G. Circadian and ultradian variations of leptin in normal man under continuous enteral nutrition: relationship to sleep and body temperature. J Clin Endocrinol Metab. 1998;83(6):1893-1899.

448. Shea SA, Hilton MF, Orlova C, Ayers RT, Mantzoros CS. Independent circadian and sleep/wake regulation of adipokines and glucose in humans. J Clin Endocrinol Metab. 2005;90(5):2537-2544.

449. Roberts CK, Hevener AL, Barnard RJ. Metabolic syndrome and insulin resistance: underlying causes and modification by exercise training. Compr Physiol. 2013;3(1):1-58.

450. Zhang EE, Liu Y, Dentin R, et al. Cryptochrome mediates circadian regulation of cAMP signaling and hepatic gluconeogenesis. Nat Med. 2010;16(10):1152-1156.

451. Marcheva B, Ramsey KM, Buhr ED, et al. Disruption of the clock components CLOCK and BMAL1 leads to hypoinsulinaemia and diabetes. Nature. 2010;466(7306):627-631.

\section{Publish your work in this journal}

Diabetes, Metabolic Syndrome and Obesity: Targets and Therapy is an international, peer-reviewed open-access journal committed to the rapid publication of the latest laboratory and clinical findings in the fields of diabetes, metabolic syndrome and obesity research. Original research, review, case reports, hypothesis formation, expert opinion and commentaries are all considered for publication. The manuscript management system is completely online and includes a very quick and fair peer-review system, which is all easy to use. Visit http://www.dovepress.com/testimonials.php to read real quotes from published authors. 